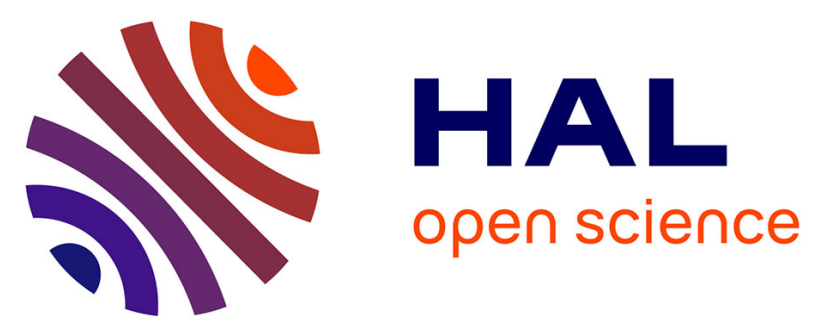

\title{
Organotypic and primary neural cultures as models to assess effects of different gold nanostructures on glia and neurons
}

Jeff Ji, Alexandre Moquin, Franck Bertorelle, Philip Ky Chang, Rodolphe Antoine, Julia Luo, R. Anne Mckinney, Dusica Maysinger

\section{To cite this version:}

Jeff Ji, Alexandre Moquin, Franck Bertorelle, Philip Ky Chang, Rodolphe Antoine, et al.. Organotypic and primary neural cultures as models to assess effects of different gold nanostructures on glia and neurons. Nanotoxicology, 2019, 13 (3), pp.285-304. 10.1080/17435390.2018.1543468 . hal-02367748

\section{HAL Id: hal-02367748 \\ https://univ-lyon1.hal.science/hal-02367748}

Submitted on 31 Oct 2020

HAL is a multi-disciplinary open access archive for the deposit and dissemination of scientific research documents, whether they are published or not. The documents may come from teaching and research institutions in France or abroad, or from public or private research centers.
L'archive ouverte pluridisciplinaire HAL, est destinée au dépôt et à la diffusion de documents scientifiques de niveau recherche, publiés ou non, émanant des établissements d'enseignement et de recherche français ou étrangers, des laboratoires publics ou privés. 


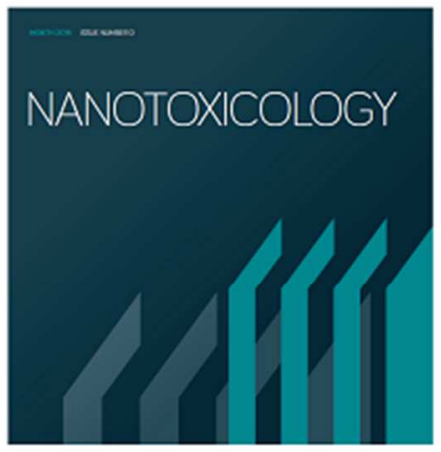

\section{Organotypic and primary neural cultures as a tool to assess effects of different gold nanostructures on glia and neurons}

\begin{tabular}{|c|c|}
\hline Journal: & Nanotoxicology \\
\hline Manuscript ID & TNAN-2018-0083.R1 \\
\hline Manuscript Type: & Original Article \\
\hline Date Submitted by the Author: & $\mathrm{n} / \mathrm{a}$ \\
\hline Complete List of Authors: & $\begin{array}{l}\text { Ji, Jeff; McGill University, Pharmacology \& Therapeutics } \\
\text { Moquin, Alexandre; McGill University, Pharmacology \& Therapeutics } \\
\text { Chang, Philip; McGill University, Pharmacology \& Therapeutics } \\
\text { Antoine, Rodolphe; Universite Claude Bernard Lyon } 1 \text { Faculte des Sciences } \\
\text { et Technologies, Institut Lumière Matière } \\
\text { Luo, Julia; McGill University, Pharmacology \& Therapeutics } \\
\text { McKinney, R. Anne; McGill University, Pharmacology \& Therapeutics } \\
\text { Maysinger, Dusica; McGill University, Pharmacology \& Therapeutics }\end{array}$ \\
\hline Keywords: & Gold nanoparticles, Dendritic spines, Glia, Lysosomes \\
\hline Abstract: & $\begin{array}{l}\text { Gold nanoparticles (AuNP) have unique physicochemical properties and } \\
\text { have been used as delivery vehicles, contrast agents, and therapeutic } \\
\text { compounds. Although the effects of AuNPs on peripheral tissues and } \\
\text { immortalized cell lines have been extensively characterized, their effects on } \\
\text { the central nervous system (CNS) are predominantly unknown. The main } \\
\text { objective of the current study was to evaluate how AuNPs of varying sizes } \\
\text { ( } 1-100 \mathrm{~nm} \text { ), shapes (clusters, spheres, rods, flowers), and surfaces impact } \\
\text { synaptic structures in the hippocampus, a brain structure often affected in } \\
\text { neurodegeneration. Using a combination of organotypic hippocampal, as } \\
\text { well as, primary neuronal, glial, and astrocytic cultures, we examined } \\
\text { AuNPs impact on hippocampal dendritic spine density, internalization in } \\
\text { various neural cells, and the status of the lysosome. Results from these } \\
\text { studies show that AuNPs with poly(ethylene glycol) surfaces (AuNPs-PEG) } \\
\text { do not substantially decrease hippocampal dendritic spine density. } \\
\text { Conversely, AuNPs coated with the detergent, CTAB, significantly }\end{array}$ \\
\hline
\end{tabular}


decreased total spine density. Interestingly we found that smaller gold nanoclusters (ca. $2 \mathrm{~nm}$ ) were more toxic than the larger gold spheres (ca. $20 \mathrm{~nm}$ ), suggesting that AuNP size, in addition to surface coating, affects spine density. In contrast to the reductions in spine density, lysosomal marker, LAMP1, increased significantly in astrocytes, suggesting that AuNPs not only enter lysosomes, but also increases lysosome biogenesis. Thus, subtle changes in dendritic spines due to the exposure to nanoparticles, including AuNPs, can be easily revealed in organotypic brain slice cultures and provide quantitative data for morphological changes in neuronal circuitries in the CNS.

\section{SCHOLARONE ${ }^{m}$ \\ Manuscripts}




\section{Organotypic and primary neural cultures as a tool to assess effects of different gold nanostructures on glia and neurons}

Jeff $\mathrm{Ji}^{\mathrm{a}}$, Alexandre Moquin ${ }^{\mathrm{a}}$, Philip KY Chang ${ }^{\mathrm{a}}$, Rodolphe Antoine ${ }^{\mathrm{b}}$, Julia Luo $^{\mathrm{a}}$, R. Anne McKinney ${ }^{\mathrm{a}}$, and Dusica Maysinger ${ }^{\mathrm{a},}$

${ }^{a}$ Department of Pharmacology \& Therapeutics, McGill University, Montreal, Canada

${ }^{b}$ CNRS, Institut Lumière Matière, Université Lyon, Université Claude Bernard Lyon 1, Lyon, France

*Corresponding author: dusica.maysinger@mcgill.ca 


\section{Abstract}

Gold nanoparticles (AuNP) have unique physicochemical properties and have been used as delivery vehicles, contrast agents, and therapeutic compounds. Although the effects of AuNPs on peripheral tissues and immortalized cell lines have been extensively characterized, their effects on the central nervous system (CNS) are predominantly unknown. The main objective of the current study was to evaluate how AuNPs of varying sizes (1-100 nm), shapes (clusters, spheres, rods, flowers), and surfaces impact synaptic structures in the hippocampus, a brain structure often affected in neurodegeneration. Using a combination of organotypic hippocampal, as well as, primary neuronal, glial, and astrocytic cultures, we examined AuNPs impact on hippocampal dendritic spine density, internalization in various neural cells, and the status of the lysosome. Results from these studies show that AuNPs with poly(ethylene glycol) surfaces (AuNPs-PEG) do not substantially decrease hippocampal dendritic spine density. Conversely, AuNPs coated with the detergent, CTAB, significantly decreased total spine density. Interestingly we found that smaller gold nanoclusters $(c a .2 \mathrm{~nm})$ were more toxic than the larger gold spheres (ca. $20 \mathrm{~nm}$ ), suggesting that AuNP size, in addition to surface coating, affects spine density. In contrast to the reductions in spine density, lysosomal marker, LAMP1, increased significantly in astrocytes, suggesting that AuNPs not only enter lysosomes, but also increases lysosome biogenesis. Thus, subtle changes in dendritic spines due to the exposure to nanoparticles, including AuNPs, can be easily revealed in organotypic brain slice cultures and provide quantitative data for morphological changes in neuronal circuitries in the CNS.

Keywords: gold nanoparticles, dendritic spines, glia, lysosomes 


\section{Introduction}

Gold nanoparticles (AuNP) have been widely explored as diagnostic and therapeutic nanomaterials due to their chemical stability and unique physicochemical properties (Daniel e Astruc, 2004; Dreaden et al., 2012; Saha et al., 2012; Maysinger et al., 2015; Baranes et al., 2016; Lavoie-Cardinal et al., 2016; Glaser et al., 2017; Liu et al., 2017; Rosa et al., 2017; Kuncic e Lacombe, 2018; Ma et al., 2018). AuNP can be synthesized in a variety of uniform shapes and sizes using reproducible methods and can be easily functionalized with thiolated ligands such as drugs or proteins (Han et al., 2007). Used as a diagnostic tool, AuNPs can be visualized by computed tomography (CT) imaging due to their dense structure that produces high X-ray attenuation (Cole et al., 2015; Meola et al., 2018). Additionally, the surface plasmon resonance of AuNP produces photoluminescence when imaged using two-photon microscopy (Wang et al., 2013). In biological systems, AuNPs are considered stable and non-immunogenic (Shukla et al., 2005). Therapeutically, one of the most promising avenues for the use of AuNP is the treatment of brain cancer (Raliya et al., 2017; Chan et al., 2018; Coluccia et al., 2018). By coupling AuNP to a pH-sensitive linker, doxorubicin, and a blood-brain barrier (BBB) permeability peptide (TAT), intravenous administration of the AuNP-drug-peptide structures can cross the $\mathrm{BBB}$ and deliver doxorubicin specifically to the low $\mathrm{pH}$ environment of brain tumors (Cheng et al., 2014). Another therapeutic approach to destroy brain tumors is to take advantage of the photoexcited heat generation by AuNP to cause photothermal ablation of tumors (Abadeer and Murphy, 2016; Huang et al., 2006; Hussein et al., 2018; Leng et al., 2018; Sung e Schuemann, 2018). Aside from cancer therapy, AuNP have been used in neuroscience to modify neuronal circuitry (Carvalho- 
de-Souza et al., 2015) and for long-term tracking of cell migration (Betzer et al., 2017). However, data determining whether AuNPs are modulators or disruptors of brain cells are still sparse and contradictory (Schulz et al., 2013; Salinas et al., 2014; Anspach et al., 2016; Baranes et al., 2016; Eom et al., 2017; Freese et al., 2017; Ruff et al., 2017; Maysinger et al., 2018; Neuschmelting et al., 2018). Hence, there is a need for AuNPs to be thoroughly investigated at the cellular level in order to assess their suitability for applications in the central nervous system (CNS). We propose the use of organotypic slice cultures as model with established quantitative techniques to monitor fine changes in postsynaptic excitatory neuronal architecture for nanotoxicology. Organotypic brain cultures are suitable for screening of neuroactive compounds, investigations of synaptic organization at the morphological and functional level. The original setup for organotypic brain cultures, the roller tube technique, was introduced by Gahwiler's group (Gahwiler, 1981; Gähwiler, 1981). We have employed organotypic hippocampal cultures from newborn animals which have matured in vitro and provided a suitable model to study morphological changes of post-synaptic dendritic spines. A strong relationship between dendritic spine density in the hippocampus and memory has been demonstrated using different behavioral assessments. For example, the acquisition of new memories in a conditioning paradigm is associated with increased spine density in CA1 hippocampal pyramidal cells in adult male rats (Leuner et al., 2003; Jedlicka et al., 2008) and female rats (Beltrán-Campos et al., 2011). Performance on two different spatial memory tasks, namely the Morris water maze and object placement, is associated with a higher dendritic spine density on hippocampal pyramidal cells in CA1 (Moser et al., 1994; Conrad et al., 2012; Eilam-Stock et al., 2012) suggesting that there is a morphological substrate for 
memory. Furthermore, cognitive decline is associated with a loss of dendritic spines and an increase in thinner immature spines (Bourne e Harris, 2007). We now provide data for different AuNP morphologies (spheres, rods, nanoflowers, and clusters) with different ligands on their surfaces and the effects on synaptic morphology. We quantified changes in both number and shape (stubby, mushroom, and thin) of postsynaptic dendritic spines in the hippocampal pyramidal neurons of mice expressing enhanced membrane tagged green fluorescent protein (eGFP) in situ in selected hippocampal neurons (Richards et al., 2005; Chang et al., 2015). Thy1-driven eGFP expression in subpopulation of hippocampal dendrites was a practical approach to quantify spine number and determine morphometric parameters of spines and reconstruct them in 3D. CNS functions strongly depend on the type and number of specific subtypes of dendritic spines and in many neurological disorders they are altered (Milatovic et al., 2010, Penzes et al., 2011). In this study we show that spine shape and number depends on the AuNP shape and surface modifications. We also show that AuNP are localized in neural cells. Considering the majority of nanostructures end up in lysosomes, we investigated if AuNP impacted lysosomal biogenesis (Behzadi et al., 2017). Previous studies have revealed a tight link between lysosomal and cellular functions (e.g. Lim e Zoncu, 2016; Carmona-Gutierrez et al., 2016). Thus, the loss of dendritic spines or shift towards more immature or weaker spines could be associated with the change in lysosomal status. Recent studies showed that perturbations in microtubule and actin dynamics alter trafficking of lysosomes, and that this is an activity-dependent process in dendrites and dendritic spines (Goo et al., 2017; Padamsey et al., 2017). Considering that gold nanoparticles could alter cytoskeletal 
proteins (Maysinger et al., 2018) they could induce morphological changes of dendritic spines.

\section{Materials and Methods}

A summary of our methodological approach and AuNP properties (shapes and surface ligands) is illustrated in Figure 1.

\section{Organotypic hippocampal slice cultures and treatment with AuNP}

Organotypic hippocampal slice cultures were prepared as previously described (Gahwiler et al., 1997). Briefly, the slice cultures were prepared from P6-8 transgenic mice that expressed membrane-targeted eGFP under the Thy-1 promoter in a subpopulation of CA1 neurons (De Paola et al., 2003). Following decapitation, hippocampi were dissected, 400 $\mu \mathrm{m}$ thick transverse slices were made, and adhered onto glass coverslips with chicken plasma clot (Cocalico Biologicals; Reamstown, PA, USA). Cultures were maintained in a roller drum incubator at $36{ }^{\circ} \mathrm{C}$ for 3 weeks prior to experimentation to allow for maturation. Culture media consisted of $25 \%$ heat-inactivated horse serum (Invitrogen GIBCO), 25\% Hank's balanced salt solution (Invitrogen GIBCO) and 50\% Basal medium Eagle (Invitrogen GIBCO) and was replaced weekly. Once ready, the cultures were incubated in serum-free medium overnight and treatments with different AuNPs $(10 \mu \mathrm{M}$ and $100 \mu \mathrm{M}$ of $\mathrm{Au}$ which correspond to low nanomolar and picomolar concentration of nanoparticle as indicated in Table S1) were applied for 24 and 72 hours. These times were selected to reveal possible subtle changes in spine density and shape which sometimes can be seen only at the later times (72h) (Falagan-Lotsch et al., 2016). The 


\begin{abstract}
following controls were included: unbound $\mathrm{CTAB}, \mathrm{GSH}, \mathrm{PEG}, \mathrm{HAuCl}_{4}$, and medium without any nanoparticles and with less than 5\% deionized water as a vehicle control. All animal care and treatment procedures were performed in accordance with guidelines set by the Canadian Council on Animal Care and McGill Animal Welfare Committee.
\end{abstract}

\title{
Confocal microscopy and dendritic spine analysis
}

Secondary or tertiary branches from basal and apical dendrites of eGFP-expressing CA1 pyramidal neurons were imaged using an upright Leica TCS SP2 confocal microscope (Leica Microsystems, Heidelberg, Germany) equipped with a HCX PL APO 63× NA 1.4 oil immersion objective or a Zeiss LSM 710 confocal microscope (Carl Zeiss MicroImaging $\mathrm{GmbH}$ ) with a W Plan-APOCHROMAT $63 \times / 1.0$ objective. Image stacks were collected at $\mathrm{Z}=0.25 \mu \mathrm{m}$ and frame-averaged four times. Image stacks were deconvolved with Huygens Essentials software (Scientific Volume Imaging, Hilversum, The Netherlands) using a full maximum likelihood extrapolation algorithm. Dendritic spine quantification was carried out using Imaris software (Imaris, Bitplane, Zürich, Switzerland). Dendritic spines were classified into three main subtypes, stubby, mushroom, and thin-type spines using previously established methods based on the measurements of spine head and neck diameters (McKinney, 2010; Maysinger et al., 2018).

\section{Animal dissection and primary dissociated cultures}

Glial cultures: Primary dissociated glial cultures were prepared from the P0-P3 postnatal C57/BL6 mice. Cortical and hippocampal tissues were dissected and placed in ice-cold 
1X Hank's-balanced saline solution (HBSS). The tissues were dissociated by mechanical trituration using a fire-polished pipette, resuspended in growth media (DMEM (ThermoFisher) $+10 \%$ FBS (Wisent $+1 \%$ Penicillin-Streptomycin $(\mathrm{P} / \mathrm{S}$, ThermoFisher). Cells were seeded onto T75 flasks coated with poly-D-lysine (PDL, Sigma). Culturing media was replaced every 2 days, 7-8 days after plating the cultures were shaken at 180 rpm in an incubator-shaker (New Brunswick Scientific, G24 Environmental Incubator Shaker) for 2 hours to isolate microglia in the media. Primary microglia were seeded onto PDL-coated coverslips and cultured in DMEM $+10 \% \mathrm{FBS}+1 \% \mathrm{P} / \mathrm{S}$ and contained $99 \%$ Iba-1-positive microglia. The glial cultures were shaken an additional 6-8 hours at 260 rpm to detach remaining microglia and oligodendrocytes. Astrocytes were finally detached by trypsin and seeded onto PDL-coated coverslips. Enriched astrocyte cultures contained $88 \%$ GFAP+ astrocytes and $8 \%$ Iba-1-positive microglia cell.

Neuronal cultures: Primary dissociated neuronal cultures were prepared from P0-P2 postnatal C57/BL6 mice. Cortical and hippocampal tissues were dissected and placed in ice-cold 1X HBSS. The tissues were softened in $0.25 \%$ trypsin $(2.5 \%$ Trypsin (ThermoFisher) diluted 10 -fold into $1 \mathrm{X} \mathrm{HBSS}$ ) for $20 \mathrm{~min}$ at $37^{\circ} \mathrm{C}$ and $0.1 \%$ DNAse I (Sigma DN25) for $5 \mathrm{~min}$ at $37^{\circ} \mathrm{C}$. Tissues were washed twice in plating media (Neurobasal medium (ThermoFisher) $+2 \mathrm{mM} \mathrm{L-glutamine} \mathrm{(ThermoFisher)}+10 \% \mathrm{FBS}+$ $1 \% \mathrm{P} / \mathrm{S}$ ) and mechanically dissociated by triturating with a fire-polished pipette. Cells were plated onto PDL (Sigma)-coated coverslips at 50,000-100,000 cells per coverslip in plating media for 24 hours and switched to serum-free maintenance media (Neurobasal medium $+2 \mathrm{mM} \mathrm{L}$-glutamine $+2 \% \mathrm{~B} 27+1 \% \mathrm{P} / \mathrm{S})$. Neuronal cultures were feed every 3 days by changing $50 \%$ of the maintenance media. All animal protocols used in this study 
were approved by the McGill University Animal Care Committee and followed the guidelines of the Canadian Council on Animal Care.

\section{Immunocytochemistry on primary cultures}

Cells were washed briefly with PBS and fixed in 4\% paraformaldehyde (PFA) for 10 min at RT. Cells were permeabilized in PBS $+0.1 \%$ Triton-X100 for $10 \mathrm{~min}$ at RT and blocked for 1 hour in PBS $+10 \%$ goat serum. Cells were incubated with rabbit antiGFAP (1:1,000, Abcam ab7260), rabbit anti-Iba1 (1:500, Wako 019-19741), mouse anti$\beta 3$ tubulin (1:500, Millipore MAB1637), rabbit anti-TFEB (1:500, Bethyl Laboratories \#A303-673), and rat anti-LAMP1 (1:250, DSHB 1D4B) in blocking solution overnight at $4{ }^{\circ} \mathrm{C}$. After PBS washes, cells were incubated with 1:500 Alexa Fluor 488 secondary goat anti-rabbit/mouse antibody (1:500) for 1 hour at RT. Cells were mounted onto microscope slides using Aqua-Poly/Mount (Polysciences). Fluorescence measurements were done using ImageJ. LAMP1 fluorescence intensity measured in arbitrary units (AU) represents the total intensity (pixels) inside the cell or nucleus divided by its crosssectional area.

\section{Two-photon luminescence}

Two-photon luminescence (TPL) imaging were performed using a Leica TCS SP-8 microscope at $63 \mathrm{x}$, an oil objective at a numeric aperture of 1.3 , a Coherent Chameleon Multiphoton V2 laser. The emission wavelength was set at $720 \mathrm{~nm}$ and the detector from $398-472 \mathrm{~nm}$ at a laser intensity of $1.8 \%$ and a pulse frequency of $80 \mathrm{MHz}$. An argon laser $(488 \mathrm{~nm})$ was used in combination to detect the cell specific markers. 


\section{Cell viability assay}

Primary neural cells (astrocytes, microglia, and neurons) were seeded in 96-well black plates (Corning) in growth media (DMEM $+10 \% \mathrm{FBS}+1 \% \mathrm{P} / \mathrm{S})$. Cells were treated with AuNP (and their ligands, CTAB, GSH, and PEG) for 24 and 72 hours in growth media. $\mathrm{HAuCl}_{4}$ was also tested at 10 and $100 \mu \mathrm{M}$. At the end of treatment, cells were incubated with $10 \mu \mathrm{M}$ Hoechst 33342 and $1.5 \mu \mathrm{M}$ propidium iodide (PI) for $10 \mathrm{~min}$ and imaged using a high-content analysis system (PerkinElmer Operetta, Columbus V2.7.1). Cell viability was determined by the number of total nuclei (Hoechst positive) subtracted by the number of dead cells (PI positive) and expressed as percentage of control.

\section{AuNP synthesis and characterization}

Material: Gold chloride trihydrate was obtained from Alfa Aesar. Sodium citrate, silver nitrate, sodium borohydride, L-ascorbic acid, cyclohexane and acetone were purchased from Sigma Aldrich. Hexadecyltrimethylammonium bromide (CTAB) was purchased from Fluka. $\alpha$-methoxy- $\omega$-mercapto poly(ethylene glycol) (MeO-PEG-SH, 5,000 g/mol) was obtained from IRIS Biotech GmbH, Germany.

Instrumentation: UV-Visible absorption spectra were recorded with an 8452A Agilent photodiode array spectrometer. ICP-AES data were acquired using a Jobin Yvon/Horiba JY200 instrument and analyzed with the ICP software "ICP Analyst v5.2". The gold ray wavelength was at $267.595 \mathrm{~nm}$.

Transmission electron micrographs (TEM) of the nanoparticles were obtained using a FEI TECNAI electron microscope operating at $120 \mathrm{kV}$. The supporting grids were 
Formvar-covered, 200-mesh copper grids. The size of the nanoparticles was determined from the electron microscopic images using a free ImageTool version 3.00, downloaded from http://ddsdx.uthscsa.edu/dig/download.html. About 100 particles were measured for each sample.

AuNP-spheres synthesis: CTAB covered spherical AuNPs $(\mathrm{d}=19 \pm 1 \mathrm{~nm})$ were prepared by adding an aqueous ice-cold $\mathrm{NaBH}_{4}$ solution $(0.500 \mathrm{~mL}, 0.01 \mathrm{M})$ to a mixture of aqueous $\mathrm{HAuCl} \bullet 3 \mathrm{H}_{2} \mathrm{O}(0.125 \mathrm{~mL}, 0.01 \mathrm{M})$ and an aqueous solution of CTAB (4.375 $\mathrm{mL}, 0.075 \mathrm{M}$ ). The seed growth was allowed to proceed for 2 hours. After this time, an aliquot of the seed solution was added to a solution obtained by adding aqueous CTAB $(1.6 \mathrm{~mL}, 0.10 \mathrm{M})$, aqueous $\mathrm{HAuCl}_{4} \bullet 3 \mathrm{H}_{2} \mathrm{O}(2 \mathrm{~mL}, 0.01 \mathrm{M})$, an aqueous ascorbic acid (AA) solution $(0.6 \mathrm{~mL}, 0.10 \mathrm{M})$ to $90 \mathrm{~mL}$ water, followed by the aged seed solution $(0.1$ mL) (Wang et al., 2008a). Immediately upon addition of the seed solution, the mixture was mixed gently for $10 \mathrm{~s}$. It was then kept undisturbed for at least 3 hours. The solutions were kept at $30{ }^{\circ} \mathrm{C}$ (in a water bath) throughout the entire procedure in order to prevent the crystallization of CTAB. At the end of the reaction, the mixture was centrifuged by an Eppendorf centrifuge model 5403 (6,000 rpm, $60 \mathrm{~min})$, Supernatants were discarded and residues were dispersed in water $(5 \mathrm{~mL})$.

AuNP-rods synthesis: gold nanorods were synthesized by a scaled-up version of the seeded growth method described previously (Sau and Murphy, 2004). Gold seeds were prepared by adding an aqueous ice-cold $\mathrm{NaBH}_{4}$ solution $(0.600 \mathrm{~mL}, 0.01 \mathrm{M})$ to a solution obtained by adding aqueous $\mathrm{HAuCl}_{4} \bullet 3 \mathrm{H}_{2} \mathrm{O}(0.250 \mathrm{~mL}, 0.01 \mathrm{M})$ to an aqueous solution of CTAB (7.5 mL, 0.10 M). The seed growth was allowed to proceed for 2 hours. After this time, an aliquot of the seed solution was added to a solution obtained by mixing, 
first, aqueous CTAB (95 mL, $0.10 \mathrm{M})$, aqueous $\mathrm{HAuCl}_{4} \bullet 3 \mathrm{H}_{2} \mathrm{O}(4 \mathrm{~mL}, 0.10 \mathrm{M})$, and aqueous $\mathrm{AgNO}_{3}(0.6 \mathrm{~mL}, 0.01 \mathrm{M})$ and, last, an aqueous AA solution $(0.64 \mathrm{~mL}, 10 \mathrm{M})$. Immediately upon addition of the seed solution, the mixture was mixed gently for $10 \mathrm{~s}$. It was then kept undisturbed for at least 3 hours. The solutions were kept at $30{ }^{\circ} \mathrm{C}$ (in a water bath) throughout the entire procedure in order to prevent the crystallization of CTAB. At the end of the reaction, the mixture was centrifuged by an Eppendorf centrifuge model 5403 (9,000 rpm, $90 \mathrm{~min}$ ). The residue (AuNP-rods) was redispersed in water and MeO-PEG-SH $(12 \mu \mathrm{L}, 25 \mathrm{mM})$ was added to this suspension $(0.3 \mathrm{~mL})$. The mixture was kept overnight. It was subjected to centrifugation (14,000 rpm, $20 \mathrm{~min})$. The residue was redispersed in water $(0.5 \mathrm{~mL})$. The concentration of atomic gold in the AuNP-rods suspension was determined by inductively coupled plasmon atomic emission spectroscopy (ICP-AES).

AuNP-flowers synthesis: CTAB coated gold nanoflowers were prepared by seed mediated process (Yu et al., 2008). Gold seeds were synthesized by adding an aqueous ice-cold $\mathrm{NaBH}_{4}$ solution $(0.1 \mathrm{~mL}, 0.03 \mathrm{M})$ to a $10 \mathrm{~mL}$ solution of aqueous $\mathrm{HAuCl}_{4} \bullet 3 \mathrm{H}_{2} \mathrm{O}(2.5 \times$ $\left.10^{-4} \mathrm{M}\right)$ and trisodium citrate $\left(2.5 \times 10^{-4} \mathrm{M}\right)$. The seed growth was allowed to proceed overnight. For growth solution, $0.75 \mathrm{~mL}$ of cyclohexane and $1.0 \mathrm{~mL}$ of acetone were added into $250 \mathrm{~mL}$ of aqueous solution containing aqueous CTAB (30 g/L) and aqueous $\mathrm{HAuCl}_{4} \bullet 3 \mathrm{H}_{2} \mathrm{O}\left(2.5 \times 10^{-4} \mathrm{M}\right)$. Without delay, $200 \mathrm{~mL}$ was taken from the lower portion of the phase separated solution and combined with the gold seed suspension $(1.2 \mathrm{~mL})$, $\mathrm{AgNO}_{3}$ aqueous solution $(0.1 \mathrm{~mL}, 0.02 \mathrm{M})$, and freshly prepared aqueous $\mathrm{AA}(10 \mathrm{~mL}$, $0.1 \mathrm{M})$. The suspension was allowed to mature at $30{ }^{\circ} \mathrm{C}$ overnight. The solutions were kept at $30{ }^{\circ} \mathrm{C}$ (in a water bath) throughout the entire procedure in order to prevent the 
crystallization of CTAB. At the end of the reaction, the mixture was centrifuged by an Eppendorf centrifuge model $5403(6,000 \mathrm{rpm}, 10 \mathrm{~min})$. The residue was redispersed in water $(3.7 \mathrm{~mL})$.

Modification with PEG: $1.6 \mathrm{~mL}$ of the CTAB-coated AuNPs was incubated with the aqueous solution of MeO-PEG-SH $5 \mathrm{kDa}(4.3 \mu \mathrm{L}, 25 \mathrm{mM})$ overnight $(75 \mu \mathrm{M}$ final concentration of polymers). The AuNPs were centrifuged (10,000 rpm, $5 \mathrm{~min}$ ) and washed with DI water to remove the excess CTAB and PEG. Some aggregation was observed. AuNPs were dispersed in an aqueous solution of PEG $(200 \mu \mathrm{M}, 1.6 \mathrm{~mL})$. The mixture was sonicated for 30 minutes and left overnight at RT. AuNP-PEG was centrifuged three times in water to remove excess free PEG and the AuNP pellet was redispersed in $1 \mathrm{~mL}$ DI water. No aggregation was observed.

\section{Au-nanoclusters-GSH synthesis and characterization}

$\mathrm{Au}_{15}(\mathrm{SG})_{13}(\mathrm{Au}-\mathrm{nanoclusters-GSH})$ were synthesized as reported (Russier-Antoine et al., 2014). The monodispersity in terms of gold cluster sizes was verified by ESI-mass spectrometry (Hamouda et al., 2013). An ESI mass spectrum for the protected $\mathrm{Au}_{15}$ cluster from solution, acquired under gentle ESI conditions is shown in Figure S1. A charge state distribution was observed from $[\mathrm{M}+5 \mathrm{H}+] 5+$ through $[\mathrm{M}+7 \mathrm{H}+] 7+$. Deconvolution of charge states from 5+ through 7+, provided a mass of $6928 \mathrm{Da}$ for the intact $\mathrm{Au}$ cluster, consistent with the calculated mass of $\mathrm{Au}_{15}(\mathrm{SG})_{13}$. The linear optical absorption spectrum of $\mathrm{Au}_{15}(\mathrm{SG})_{13}$ is composed by a shoulder band at $\sim 370 \mathrm{~nm}$, and the energy gap is determined to be $\sim 2.5 \mathrm{eV}$ (at zero absorbance). . Photoluminescence quantum yields are low in aqueous solutions, typically lower than $4 \times 10^{-3}$. Size determination of $\mathrm{Au}_{15}(\mathrm{SG})_{13}$ clusters indicates a diameter of $1.6 \mathrm{~nm}$ and a hydrodynamic 
diameter of $2.9 \mathrm{~nm}$ (Soleilhac et al., 2017). Au-nanoclusters coated with CTAB could not be prepared as the force between thiol groups of GSH and $\mathrm{Au}$ atoms in the dative bonds are stronger $(c a .1 \mathrm{nN})$ (Xue et al., 2014) compared to the non-covalent surfactantcoating of the gold structures and the CTAB molecules.

$\mathrm{Au}_{25}(\mathrm{SG})_{18}$ which served as a spherical control were synthesized as follow: $234 \mathrm{mg}$ of glutathione (GSH) was dissolved in $35 \mathrm{~mL}$ of methanol, $2 \mathrm{~mL}$ of tributylamine and $2 \mathrm{~mL}$ of triethylamine. Then $100 \mathrm{mg}$ of $\mathrm{HAuCl}_{4}, 3 \mathrm{H}_{2} \mathrm{O}$ dissolved in $10 \mathrm{~mL}$ of water was added and the solution was stirred 3 hours at $45^{\circ} \mathrm{C}$. The solution was cooled to ambient temperature and $50 \mathrm{mg}$ of tetramethylammonium borohydride was added under strong stirring. 1 hour later another $25 \mathrm{mg}$ of borohydride was added and the solution was stirred 3 hours. The solution was left undisturbed overnight before purification. Precipitation of Au-nanoclusters was induced by adding $1 \mathrm{~mL}$ of $\mathrm{NH}_{4} \mathrm{OH} \quad 10 \%$ and diethyl ether. The unwanted products were removed with cycles of dissolution/precipitation/centrifugation. The powder was dissolved in a minimum of $\mathrm{H}_{2} \mathrm{O} / \mathrm{NH}_{4} \mathrm{OH}$ then precipitated with methanol. After centrifugation, the powder was dissolved again in $10 \mathrm{~mL}$ of water. Then $2 \mathrm{~mL}$ of glacial acetic acid was added and the solution was left undisturbed for 1 hour before being centrifuged. The supernatant was collected and precipitated with methanol. Another cycle of dissolution/precipitation with $\mathrm{H}_{2} \mathrm{O} / \mathrm{NH}_{4} \mathrm{OH}$ and acetic acid was done before drying the powder under vacuum over $\mathrm{P}_{2} \mathrm{O}_{5}$.

The as-prepared Au-nanoclusters-GSH were characterized by mass spectrometry. The monodispersity in terms of the size of the prepared gold clusters was verified by ESImass spectrometry (Figure S1). Russier-Antoine et al. (Russier-Antoine et al., 2014) and Soleilhac et al. (Soleilhac et al., 2017) reported the linear optical absorption spectra with 
an absorbance shoulder for Au-nanoclusters at $c a .500 \mathrm{~nm}$ and a broad emission band in the near-IR region centered around $650-700 \mathrm{~nm}$. The energy gap of $\mathrm{Au}_{25}(\mathrm{SR})_{18}$ is $\sim 1.3$ $\mathrm{eV}$.

\section{Characterization of AuNP by field flow fractionation (AF4)}

The AF4 separation was performed on an Agilent 1100 (Agilent Technologies) combined with a short channel (SC) separation channel linked to Wyatt Eclipse DualTec (Wyatt Technology, Santa Barbara, CA, USA), coupled with a UV-Vis detector SPD-20A (Shimadzu Co., Kyoto, Japan), a fluorescence detector (RF-10AXL, Shimadzu Co.), and a dynamic light scattering detector (WyattQELS, Wyatt Technology) which is an add-on unit connected to the multi-angle light scattering detector (Dawn Heleos 8+ detector, Wyatt Technology). The light scattering detector was equipped with a K5 cell and a GaAs laser operating at $658 \mathrm{~nm}$. The separation channel equipped with a $350 \mu \mathrm{m}$ spacer (Wyatt Technology), a length of $15.5 \mathrm{~cm}$ and a width from 2.1 to $0.1 \mathrm{~cm}$ and a regenerated cellulose membrane with a cut-off of $10 \mathrm{kDa}$ from Nadir (Wiesbaden, Germany). The samples were measured at $0.5 \mathrm{~s}$ intervals and the UV and MALS signals were simultaneously recorded as fractograms, plots of detector signal intensity versus time. Data acquisition and processing were performed using ASTRA $^{\circledR}$ ver. 6.1.1.17 (Wyatt Technology).

\section{AF4 fractionation method}

The fractionations of AuNP of different shapes and sizes were evaluated in $10 \mathrm{mM}$ phosphate buffer at $\mathrm{pH}$ 7.0. The buffers were passed through a $0.1 \mu \mathrm{m}$ Whatman ${ }^{\circledR}$ filter 
(GE Healthcare Life Sciences, Pittsburgh, PA, USA) prior to use. The channel flow rate was kept constant at $0.3 \mathrm{~mL} / \mathrm{min}$. After flow equilibration, the sample was injected with a flow rate of $0.2 \mathrm{~mL} / \mathrm{min}$, followed by a $5 \mathrm{~min}$ focusing period with a cross-flow rate of $1.2 \mathrm{~mL} / \mathrm{min}$. Following a $1 \mathrm{~min}$ transition, a two-step cross-flow rate gradient was initiated for the elution mode. The starting cross-flow rate $(1.2 \mathrm{~mL} / \mathrm{min})$ was decreased linearly to $0 \mathrm{~mL} / \mathrm{min}$ within $20 \mathrm{~min}$. The cross-flow rate was then kept constant at 0.0 $\mathrm{mL} / \mathrm{min}$ for $10 \mathrm{~min}$ to allow elution of any large aggregates. The detector flow rate was kept at $0.3 \mathrm{~mL} / \mathrm{min}$ throughout. The detection of the eluted fractionated polymers and drug was performed sequentially by UV absorbance at $520 \mathrm{~nm}$, MALS, and DLS. The Zaverage effective spherical hydrodynamic radius of the eluting particles/agglomerates was determined by DLS based on cumulant analysis of the scattered intensity correlation functions measured across each eluting band. Each fractogram presented is representative of a triplicate sample.

\section{AF4 data analysis}

The sizes of the AuNP were calculated from the multi-angle light scattering data. The UV signals in the fractograms were normalized automatically by software by scaling the data against the absorbance measured from the AuNPs at $520 \mathrm{~nm}$.

\section{Statistical analysis}

All data are expressed as mean \pm SEM and analyzed by one-way ANOVA, as indicated. All values were obtained from at least three independent experiments. When a significant effect was obtained with one-way ANOVA, Dunnett's test was used to compare all 
values to the control. Alternatively, Student's t-test was used to analyze significant differences between two group means. Statistical analyses were performed using $\mathrm{R}$ (v3.2.2). $\mathrm{p}<0.05$ was considered significant. 


\author{
Results \\ [insert Figure 1]
}

\title{
Characterization of gold nanoparticles
}

Gold nanospheres (AuNP-spheres), nanorods (AuNP-rods), and flowers (AuNP-flowers) surfaces were modified using thiolated $5 \mathrm{kDa}$ PEG. Transmission electron microscopy and AF4 were used to determine the sizes and shapes of the AuNP. UV-absorbance spectrophotometry was used to determine the absorption spectra. After functionalization with PEG, the AuNP-spheres had a narrow size distribution and hydrodynamic sizes of $\mathrm{D}_{\mathrm{h}}=36.1 \mathrm{~nm}$ (data not shown). AuNP-rods showed representative double absorption peaks corresponding to the two dimensions of the AuNP-rods, the aspect ratio was determined to be 3 by TEM $(15 \times 45 \mathrm{~nm})$. By AF4, the elution shows a narrow peak with hydrodynamic radii of $c a .4 \mathrm{~nm}$ (data not shown) and root-mean square (rms) radii of $c a$. $12 \mathrm{~nm}$. Using the same separation conditions, AuNP-flowers eluted out at much later times compared to the AuNP-spheres (elution peak at 23.7 min vs. 16.6 min for the spheres and 19.2 min for the rods). The synthesis of AuNP-flowers leads to much more size dispersion compared to the synthesis of AuNP-spheres and AuNP-rods, as confirmed by TEM imaging. While the AuNP-spheres are very narrowly distributed, the AuNPflowers are very broadly distributed with sizes ranging from $40 \mathrm{~nm}$ to $160 \mathrm{~nm}$ and a median size at $77 \pm 6 \mathrm{~nm}$ as determined by TEM. By AF4, the rms radius of the flowers was $55.2 \pm 1.3 \mathrm{~nm}$. The broad size distribution and multi dimensionality of the AuNPflowers explains the broad absorbance region and the absence of a defined peak. The hydrodynamic diameters of the Au-nanoclusters were determined by DLS and equal to $\mathrm{D}_{\mathrm{h}}=2.9 \mathrm{~nm}$ for the $\mathrm{Au}_{15}(\mathrm{SG})_{13}$ with an absorption peak at $370 \mathrm{~nm}$, and $\mathrm{D}_{\mathrm{h}}=3.3 \mathrm{~nm}$ for 
the $\mathrm{Au}_{25}(\mathrm{SG})_{18}$ with two absorption peaks at $435 \mathrm{~nm}$ and $660 \mathrm{~nm}$ as previously reported (Solheilhac et al., 2017; Russier-Antoine et al., 2014).

[Insert Figure 2]

The stability of the Au-nanoclusters, AuNP-spheres, AuNP-rods, and AuNP-flowers coated with GSH or PEG was assessed in water, cell culture media without and with serum proteins $(10 \%$ fetal bovine serum). Determination of the sizes of nanoparticles in cell culture media is highly relevant to study the effect of physiological concentrations of salts on nanoparticle stability. Supplementation with serum proteins was used to study the effect of serum proteins which may lead to the formation of a protein corona on the AuNP surfaces. Table S2 reports the average hydrodynamic diameters, the polydispersity index and the light scattering intensity of the various gold nanoparticle preparations diluted to $100 \mu \mathrm{M} \mathrm{Au}$. Au-nanoclusters were too small and at a too low dilution to obtain reliable size data. There was no significant change in the sizes of larger AuNP structures (AuNP-rods and AuNP-flowers) when exposing them to cell culture media with or without serum proteins. The AuNP-spheres-GSH, on the other hand, formed large agglomerates in the presence of physiological salt concentrations. PEGylation of the surface prevented agglomeration of the AuNP-spheres at 0 and 24-hour incubation. Addition of serum proteins to the cell culture media increased slightly the sizes of AuNPspheres-GSH (from $39.7 \mathrm{~nm}$ in water to $56.5 \mathrm{~nm}$ ) at time $0 \mathrm{~h}$ which did not agglomerate as much as the AuNP-spheres-GSH in cell culture media $(417.7 \mathrm{~nm})$. This could be because of the formation of a protein corona on the surface of the AuNP-spheres-GSH which prevented further agglomeration of the nanoparticles. 


\section{Effect of AuNP on dendritic spine morphology}

Compared to primary dissociated single-cell cultures organotypic slice culture models are closer to an in vivo situation (Humpel, 2015). While some investigations in organotypic cultures can be applied as acutely prepared slices, the advantage of such preparations is that experiments that require long-term survival up to 4 months can be carried out (e.g. chronic exposure to toxic agents and nanomaterials). Organotypic slice cultures can be maintained for many months and retain the cytoarchitecture of the tissue of origin (Gahwiler et al., 1997).

We first assessed the effects of PEG-coated AuNPs have on hippocampal dendritic spine morphology in organotypic hippocampal slice cultures. PEG is a hydrophilic group used to stabilize many FDA approved synthetic drugs (Li et al., 2013). Different PEGs have been used for preparation of nanodelivery systems; larger PEGs can cause some undesirable responses in vitro and in vivo (Dobrovolskaia et al., 2016). To account for size variations between the different shapes of nanoparticles, we standardized the treatment concentration of AuNP to the concentration of molecular gold atoms. Calculated number of gold atoms and per nanoparticle is summarized in Supplemental Table 1. Exposure to $10 \mu \mathrm{M}$ and $100 \mu \mathrm{M}$ of $\mathrm{Au}$ in the form of AuNP-flowers-PEG or AuNP-rods-PEG for 24 hours or 72 hours did not significantly alter dendritic spine morphology or total spine density (Figure 3). The Au concentrations of $10 \mu \mathrm{M}$ and 100 $\mu \mathrm{M}$ correspond to picomolar to nanomolar concentrations in gold nanoparticles which are within the doses tested clinically (Wang et al., 2016; Balasubramanian et al., 2010). The treatment with $30 \mu \mathrm{M}$ AuNP-spheres-PEG led to a transient decrease in thin-type spines after 24 hours that reverted to control levels after 72 hours. 
[Insert Figure 3]

Next, we tested whether CTAB coated AuNP affected spine density, as CTAB is a commonly used detergent during AuNP synthesis. CTAB coated gold nanoparticles lead to a significant reduction in dendritic spines, revealing the deleterious effects of CTAB alone or on the surface of gold nanoparticles. This reduction in spine density illustrates that gold nanoparticle should always be extensively purified because any leftover CTAB would produce undesirable effects which could be misinterpreted as undesirable effects of gold nanoparticles. In contrast to AuNP-PEG, both AuNP-flowers-CTAB and AuNProds-CTAB AuNP-CTAB dramatically reduced total spine density (Figure 4). In particular, mature more stable mushroom-type spines were the most effected and significantly decreased by both AuNP-flowers-CTAB and AuNP-rods-CTAB. AuNProds-CTAB proved extremely toxic at $100 \mu \mathrm{M}$ that resulted in the destruction of the organotypic cultures after 72 hours (see extensive distortion of dendritic spines caused by CTAB: Figure S4C). Both AuNP-flowers-CTAB and AuNP-rods-CTAB lowered spine density in a concentration- and time-dependent manner, with the greatest loss at the highest concentration (concentration) and longest time (72 hours) of exposure (Figure 4B).

[Insert Figure 4]

\footnotetext{
AuNP-rods-CTAB were cytotoxic to all neural cell types (Figure S3) and they significantly reduced the spine density (Figure 4B). GSH and PEG as surface ligands are not cytotoxic in nanomolar concentrations in primary cortical cultures (Figure S4A). The
} 
treatment with $\mathrm{HAuCl}_{4}(10 \mu \mathrm{M}$ and $100 \mu \mathrm{M})$ causes significant reduction in spine density after $72 \mathrm{~h}$ (Figure S4B). These ligands have been selected because intracellular GSH replaces most of the ligands from the surface of AuNPs. Intracellular concentrations of GSH are within the high millimolar concentrations $(1-10 \mathrm{mM})$ depending on the cell type. GSH plays a critical protective role in cells under oxidative stress. We anticipated that GSH-modified AuNP would be non-toxic. PEGs with molecular weights of 5,000 Da are commonly used as surface ligands to enhance AuNP stability (Bergeron et al., 2015) and we have previously shown that this ligand did not significantly damage brain structures in vivo (Hutter et al., 2010). Au-nanoclusters and other gold nanomorphologies are commonly functionalized with glutathione (GSH), an endogenous antioxidant and a markedly smaller molecule than PEG (Zhang et al., 2012, Zhang et al., 2015). Both Aunanoclusters and AuNP-spheres were coated with non-toxic, GSH to avoid possible ligand-dependent confounding effect. While both $10 \mu \mathrm{M}$ Au-nanoclusters-GSH and AuNP-spheres-GSH decreased mushroom-type spine and total spine densities after 72 hours, Au-nanoclusters-GSH caused the greatest loss in mushroom-type spine and total spine densities. Interestingly, neither Au-nanoclusters-GSH nor AuNP-spheres-GSH treatment decreased cell viability after $24 \mathrm{~h}$ in organotypic cultures or dissociated astrocytes (Supplemental Figure 2), suggesting their action on dendritic spines is not due to acute astrocyte toxicity. It is well documented that astrocytes can profoundly alter dendritic spine morphology (Haber et al., 2006; Verbich et al., 2012; Perez-Alvarez et al., 2014; Allen e Eroglu, 2017).

[Insert Figure 5] 
Collectively, our experiments revealed that PEG-coated AuNP did not significantly affect spine density, whereas those with CTAB did regardless of their size. Small $(<3 \mathrm{~nm}) \mathrm{Au}-$ nanoclusters-GSH reduced spine density suggesting that these small clusters can easily enter cellular compartments and change cellular homeostasis. Interestingly it also appeared that the mushroom-type spines were particularly sensitive to these AuNP treatments.

\section{Neural cell response to internalized AuNP}

Given that AuNP-PEG did not adversely affect spine density, we next assessed whether these AuNPs were internalized or simply remained in the culture media. To study cellspecific responses, we used primary astrocyte, microglia, and enriched neuronal cultures as opposed to the more complex organotypic slice cultures. Gold nanoparticles were internalized mostly by microglia, less in astrocytes and least in neurons. This trend was observed both in mixed and enriched neural cultures. We focused on AuNP-flowers due to their broad absorbance spectra for ease of imaging and limited available information on AuNP-flowers. Two-photon luminescent microscopy revealed that AuNP-flowersPEG was internalized by astrocytes, microglia, and neurons (Figure 6); After 18 hours of incubation with $100 \mu \mathrm{M}$ AuNP-flowers-PEG, AuNP-flowers were found in astrocytes (GFAP labelled), microglia (Iba-1 labelled), and neurons ( $\beta 3$-tubulin labelled). Due to the overwhelming presence of AuNP-flowers-PEG in the different cell-types, we investigated the degree of cell viability in these cultures. It appeared that AuNP-PEG did not significantly affect the viability of astrocytes or microglia. Similarly to the untoward effects of AuNP-rods-CTAB on mushroom-shaped spines, these CTAB-coated AuNP 
were highly cytotoxic (Figure S3, $10 \mu \mathrm{M}$ AuNP-rods-CTAB killed > 95\% neural cells); thus, we used AuNP-rods-CTAB for comparison with other AuNPs in cytotoxicity assays (Figure 4). The key finding from these studies is that CTAB induces cytotoxicity to neural cells whereas $\mathrm{PEG}<100 \mu \mathrm{M}$ concentrations does not.

[Insert Figure 6]

Considering that many nanoparticles end up in lysosomes (Behzadi et al., 2017) and that AuNP in our studies appeared as cytoplasmic puncta in neural cells (Figure 6) suggest that AuNP are sequestered into lysosomes. By immunolabelling lysosomes with LAMP1 and the transcription factor TFEB, a master switch for the activation of autophagy and lysosome biogenesis, we examined whether AuNP internalization altered lysosome biogenesis. Incubation of $10 \mu \mathrm{M}$ AuNP-flowers-PEG or AuNP-flowers-CTAB for 24 hours significantly increased TFEB nuclear translocation in glial cells (Figure 7A). Seeing the increase in TFEB activation, we tested for changes in lysosome regulation using antibodies against LAMP1, a constitutively expressed protein on the surface of lysosomes. LAMP1 was significantly increased in GFAP-positive astrocytes with either $10 \mu \mathrm{M}$ AuNP-flowers-PEG or AuNP-flowers-CTAB treatment after 24 hours incubation (Figure 7B).

[Insert Figure 7]

\section{Discussion}

In the present study, we used organotypic hippocampal slices and primary neural cultures to investigate the impact of AuNP of differing size, shape, and surface on dendritic spine 
morphology and lysosome activation. Our results show that (1) AuNP-flowers-PEG, AuNP-rods-PEG, and AuNP-spheres-PEG do not alter spine density, (2) AuNP-flowersCTAB and AuNP-rods-CTAB decrease spine density in a concentration and timedependent manner, (3) smaller Au-nanoclusters-GSH lead to greater loss of spines compared to larger AuNP-spheres-GSH or $\mathrm{Au}_{25}(\mathrm{SG})_{18}$ (JEFF Figure S...), (4) AuNPflowers-PEG are avidly internalized by neurons as well as glial cells, (5) AuNP-flowersPEG and AuNP-flowers-CTAB can activate TFEB and stimulate lysosome biogenesis. Both organotypic slice cultures and primary dissociated neural cultures are complementary biological models for studying nanoparticle toxicity. Three-dimensional organotypic cultures can reveal sensitive changes in spine density, whereas primary dissociated cultures are favorable for investigating cell type-dependent uptake of nanoparticles and associated intracellular regulatory processes.

$\mathrm{Au}_{15}(\mathrm{SG})_{13}$ are amongst the smallest $\mathrm{Au}$-nanoclusters reported. Although the crystallization of $\mathrm{Au}_{15}(\mathrm{SG})_{13}$ has not yet been achieved, theoretical studies predict an asymmetric structure formed by a tetrahedral $\mathrm{Au}_{4}$ kernel surrounded by [Au(I)-SR] pentamer in the ligand shell together with two regular trimer motifs (Jiang et al., 2013). There are $11 \mathrm{Au}$ cations involved in possible catalytic reactions as suggested by the reported work by Rongchao Jin (Li et al., 2014).

$\mathrm{Au}_{25}(\mathrm{SR})_{18}$ clusters have been more extensively studied (Kang et al., 2018). The symmetric structure of $\mathrm{Au}_{25}(\mathrm{SR})_{18}$ consists of an quasi-icosahedral $\mathrm{Au}_{13}$ kernel fully protected by 6 dimeric staples (4 -SR-Au-SR- and 2 -SR-Au-SR-Au-SR- staple motifs) giving it a spherical shape (Zhu et al., 2008). 
We found that the mushroom-type spines were most sensitive to the effect of AuNPflowers-CTAB and Au-nanoclusters-GSH, showing greater loss compared to thin- or stubby -spines. Although dendritic spines can undergo dynamic actin-dependent morphological modification (Fischer et al., 1998), an overall shift in any one specific spines subtypes could indicate a change in the strength of excitatory synaptic transmission. Mushroom spines contain the greatest concentration of postsynaptic density proteins, including glutamate receptors (Arellano et al., 2007) and represent the most mature spine type which can persist over several months in vivo (Grutzendler et al., 2002, Holtmaat et al., 2005, Zuo et al., 2005). Therefore, a decrease in mushroom spine density could result in a net weakening of the overall excitatory synaptic transmission. Actin filament growth and retraction is a principle driver of alterations in spine morphology (Ebrahimi and Okabe, 2014). Thus, time lapse experiments to follow the organelle movements and actin spatio-temporal organization in real time (Hotulainen and Hoogenraad, 2010) could provide further insight into structure- function relationship between cytoskeleton and neural cell communication.

Our finding that AuNP-PEG do not significantly alter the spine density is in line with current literature which supports PEG as a suitable nanoparticle ligand (Yah, 2013) for biological applications. However, a study of AuNP-rods-PEG in several cell lines (SKBR3, CHO, C2C12, HL60) shows a greater toxicity in HL60 cells which induced rapid and substantial cell loss (Rayavarapu et al., 2010). Similarly, our findings show a cell type-dependent cytotoxic effect of AuNPs; $100 \mu \mathrm{M}$ AuNP-flowers-PEG exerts greater toxicity in astrocytes compared to neurons and microglia. Previously, we have shown that intranasal administration of AuNP-rods-PEG significantly induced TLR2 
activation in microglia in vivo, with a biphasic peak at 24 hours and 7 days post administration (Hutter et al., 2010). Interestingly, microglia were less sensitive to PEGconjugated gold nanourchins and spheres in vitro (Hutter et al., 2010) compared to in vivo. This evidence further suggests that the toxic effects of AuNP is cell-type specific and must be evaluated in different cell types. Neurons, microglia, and astrocytes have different intrinsic functions but also form an interdependent network. It is important to evaluate neural cells both in isolation and in heterogeneous environment such as in the organotypic slice where the architecture and cellular communication is better preserved than in dissociated cultures. In contrast to AuNP-PEG, AuNP-CTAB severely disrupted neuronal cytoarchitecture by reducing mushroom-type spines and total spine density. CTAB is a detergent used in the synthesis of AuNP. CTAB on the surface of AuNP or insolution can lead to cell membrane and mitochondria damage that causes cell death. AuNP-spheres-CTAB induced cytotoxicity in human keratinocytes (Wang et al., 2008b) and AuNP-rods-CTAB of varying sizes increased ROS production and reduced cell viability in MCF-7 cells (Qiu et al., 2010).

The size of AuNP plays a role in nanoparticle internalization and cellular toxicity because of different cellular and tissue distribution (Fratoddi et al., 2015). Our findings show that small Au-nanoclusters-GSH (1.6 nm) significantly reduced mushroom spine density compared to larger AuNP-spheres-GSH (ca. $20 \mathrm{~nm})$. Small (1-2 nm) Au-nanoclusters are known to penetrate the nuclei and bind to DNA (Tsoli et al., 2005). $1.4 \mathrm{~nm} \mathrm{Au-}$ nanoclusters were found to decrease cell viability in multiple cell lines including fibroblasts, epithelial cells, macrophages, and melanomas and induced both apoptosis and 
necrosis after 12 hours treatment (Pan et al., 2007). On the other hand, glutathione capped gold clusters $\left(\mathrm{ca} . \mathrm{Au}_{25}\right)$ tested in $\mathrm{SH}-\mathrm{SY} 5 \mathrm{Y}$ human neuroblastoma cell cultures did not decrease cell viability even at high concentrations $(400 \mu \mathrm{g} / \mathrm{mL})$ (Polavarapu et al., 2011). Cellular uptake and in particular $\mathrm{Au}$ content in NCM460 epithelial cells was explored by Xie and colleagues (Tay et al., 2014). They showed a low cell uptake for $\mathrm{Au}_{15}(\mathrm{SG})_{13}$, which may be attributed to the zwitterionic character of the GSH ligand hindering cellular uptake. Also, negligible cytotoxicity was observed in $\operatorname{Au}_{15}(\mathrm{SG})_{13}$ exposed NCM460 epithelial cells with concentration of Au-nanoclusters up to $10 \mu \mathrm{M}$. Interestingly, capping $1.4 \mathrm{~nm}$ Au-nanoclusters with GSH prevented the acute cytotoxic effects compared to $1.4 \mathrm{~nm}$ Au-nanoclusters capped with triphenylphosphine monosulfonate, which caused cell necrosis due to oxidative stress (Pan et al., 2009). Surface chemistry, size and shape of the gold nanoparticles will affect cellular uptake (Dykman e Khlebtsov, 2014; Chandran et al., 2017; Talamini et al., 2017).

Au-nanoclusters-GSH did not cause significant cell death but they did alter the spine shape and number suggesting that AuNP can alter spine plasticity without compromising cell survival. Mechanisms which alter spine morphology, apart from those involved in cell death, include changes to local calcium transients (Segal, 2001) which affect actin mobilization (Mikhaylova et al., 2018) and receptor trafficking (Colgan and Yasuda, 2014). An example, of AuNP size-dependent functional changes in neurons is well illustrated in case of AuNPs coupled to memantine ( $c a .13 \mathrm{~nm}$ diameter). These small AuNPs can selectively modulate extrasynaptic NMDA receptor activity through steric blockage at the synaptic cleft (Savchenko et al., 2016); unlike the larger $20 \mathrm{~nm}$ AuNPspheres. Small (1-2 nm) Au-nanoclusters in our studies would potentially have access to 
the synaptic clefts and could potentially alter synaptic transmission and induce a morphological change in synaptic structure without killing neurons.

Many internalized nanoparticles, including AuNP, have been previously reported to be sequestered in lysosomes (Liu et al., 2017). We found that 24 hours incubation with AuNP-flowers-PEG and AuNP-flowers-CTAB increased TFEB nuclear translocation and LAMP1 expression in astrocytes. TFEB is a master regulator of autophagy and lysosomal biogenesis that is activated during starvation to upregulate recycling of cellular components for nutrient (Raben and Puertollano, 2016). Several studies have shown that treatments with quantum dots (Neibert and Maysinger, 2012), polystyrene nanoparticles (Song et al., 2015), and ceria nanoparticles (Song et al., 2014) can induce TFEB nuclear translocation, likely involving receptor-mediated endocytosis triggering TFEB activation (Stern et al., 2012, Gray et al., 2016, Pastore et al., 2016). Cells can store AuNP many weeks after internalization (Gunduz et al., 2017) and therefore, persistent accumulation of AuNP in lysosomes could act similar to lysomotropic agents and cause the enlargement, loss of function, and lysosome leakage (Stern et al., 2012). Upregulation of lysosomes may be a compensatory response to eliminate AuNP more effectively. AuNP are known to increase autophagy in human lung fibroblasts, as shown by the upregulation of MAP-LC3 and ATG7 (Li et al., 2010) or decrease autophagy, which leads to p62 accumulation (Ma et al., 2011). Inhibition of autophagy and mitophagy lead to the accumulation of damaged mitochondria, increased cellular ROS production, and apoptosis. Autophagy impairment and mitochondrial dysfunction is the central paradigm that underlies many neurodegenerative diseases (Banerjee et al., 2010, Jiang and 
Mizushima, 2014, Burte et al., 2015). An interesting avenue of research would be to establish the long-term effects of AuNP treatment on the mechanisms implicated in the CNS autophagy, mitochondrial plasticity and function. Lysosomes regulate the structural plasticity of dendritic spines (Goo et al., 2017; Padamsey et al., 2017).

In summary, we provide novel findings on the effects of AuNP with different shape, size, and surfaces on dendritic spine morphology implicated in CNS functions, and lysosomal biogenesis in neural cells. Our quantitative data suggest that organotypic brain tissue slices and primary neural cells are useful models for the assessment of morphological (e.g. spine number and shape) and functional (e.g. lysosomal biogenesis) properties of the neural cells exposed to AuNPs. Our data suggest that these models could be useful for screening different kinds of nanoparticles and nanostructured materials.

\section{Acknowledgements}

Drs. Maysinger, McKinney, acknowledge financial support by the Canadian Institute of Health Research (CIHR; MOP-119425, and MOP-133411). DM and RAM, acknowledge the support by grants from the Natural Sciences and Engineering Research Council of Canada (NSERC; \#RGPIN 04994-15 and Discovery Grant \#RGPIN 04774-15). Dr. Antoine acknowledges the financial support of Université de Lyon through the Program "Investissements d'Avenir" (ANR-1 1-IDEX-0007). Franck Bertorelle is acknowledged for Au-nanoclusters-GSH synthesis.

\section{Declaration of Interests}


The authors report no conflicts of interest.

\section{References}

Abadeer, N. S., and C. J. Murphy. 2016. "Recent Progress in Cancer Thermal Therapy Using Gold Nanoparticles.” Journal of Physical Chemistry C 120 (9): 4691-4716.

Allen, N. J., and C. Eroglu. 2017. "Cell Biology of Astrocyte-Synapse Interactions.” Neuron 96 (3): 697-708. doi: 10.1016/j.neuron.2017.09.056

Anspach, L., R. E. Unger, C. Brochhausen, M. I. Gibson, H. A. Klok, C. J. Kirkpatrick, and C. Freese. 2016. "Impact of Polymer-Modified Gold Nanoparticles on Brain Endothelial Cells: Exclusion of Endoplasmic Reticulum Stress as a Potential Risk Factor." Nanotoxicology 10 (9): 1341-1350. doi: $10.1080 / 17435390.2016 .1214761$

Arellano, J. I., R. Benavides-Piccione, J. Defelipe, and R. Yuste. 2007. “Ultrastructure of Dendritic Spines: Correlation Between Synaptic and Spine Morphologies.” Frontiers in Neuroscience 1 (1): 131-143.

Balasubramanian, S. K., J. Jittiwat, J. Manikandan, C. N. Ong, L. E. Yu, and W. Y. Ong. 2010. "Biodistribution of Gold Nanoparticles and Gene Expression Changes in the Liver and Spleen after Intravenous Administration in Rats.” Biomaterials 31 (8): 2034-2042. doi: 10.1016/j.biomaterials.2009.11.079

Banerjee, R., M. F. Beal, and B. Thomas. 2010. “Autophagy in Neurodegenerative Disorders: Pathogenic Roles and Therapeutic Implications.” Trends in Neurosciences 33 (12): 541-549. 
Baranes, K., M. Shevach, O. Shefi, and T. Dvir. 2016. "Gold Nanoparticle-Decorated Scaffolds Promote Neuronal Differentiation and Maturation." Nano Letters 16 (5): 2916-2920. doi: 10.1021/acs.nanolett.5b04033

Behzadi, S., V. Serpooshan, W. Tao, M. A. Hamaly, M. Y. Alkawareek, E. C. Dreaden, D. Brown, A. M. Alkilany, O. C. Farokhzad, M. Mahmoudi. 2017. “Cellular Uptake of Nanoparticles: Journey Inside the Cell." Chemical Society Reviews 46, $4218-4244$.

Beltrán-Campos, V., R. A. Prado-Alcalá, U. León-Jacinto, A. Aguilar-Vázquez, G.L. Quirarte, V. Ramírez-Amaya, and S. Díaz-Cintra. 2011. "Increase of Mushroom Spine Dnsity in CA1 Apical Dendrites Produced by Water Maze Training is Prevented by Ovariectomy" Brain Research 1369: 119-130. doi: 10.1016/j.brainres.2010.10.105

Bergeron, E., C. Boutopoulos, R. Martel, A. Torres, C. Rodriguez, J. Niskanen, J. J. Lebrun, et al. 2015. "Cell-Specific Optoporation with Near-Infrared Ultrafast Laser and Functionalized Gold Nanoparticles." Nanoscale 7 (42): 17836-17847. doi: $10.1039 / \mathrm{c} 5 \mathrm{nr} 05650 \mathrm{k}$

Betzer, O., R. Meir, M. Motiei, G. Yadid, and R. Popovtzer. 2017. “Gold NanoparticleCell Labeling Methodology for Tracking Stem Cells Within the Brain.” Nanoscale Imaging, Sensing, and Actuation for Biomedical Applications XIV, 10077.

Bourne, J., and K. M. Harris. 2007. "Do Thin Spines Learn to Be Mushroom Spines that Remember?" Current Opinion in Neurobiology 17 (3): 381-386. doi: 10.1016/j.conb.2007.04.009 
Burte, F., V. Carelli, P. F. Chinnery, and P. Yu-Wai-Man. 2015. "Disturbed

Mitochondrial Dynamics and Neurodegenerative Disorders." Nature Reviews Neurology 11 (1): 11-24.

Carmona-Gutierrez, D., A. L. Hughes, F. Madeo, and C. Ruckenstuhl. 2016. “The Crucial Impact of Lysosomes in Aging and Longevity." Ageing Research Reviews 32: 2-12. doi: 10.1016/j.arr.2016.04.009

Carvalho-De-Souza, J.L., J. S. Treger, B. Dang, S. B. H. Kent, D. R. Pepperberg, and F. Bezanilla. 2015. "Photosensitivity of Neurons Enabled by Cell-Targeted Gold Nanoparticles.” Neuron 86 (1): 207-217.

Chan, T. G., S. V. Morse, M. J. Copping, J. J. Choi, and R. Vilar. 2018. "Targeted Delivery of DNA-Au Nanoparticles across the Blood-Brain Barrier Using Focused Ultrasound." ChemMedChem 2018. doi: 10.1002/cmdc.201800262 Chandran, P., J. E. Riviere, and N. A. Monteiro-Riviere. 2017. "Surface Chemistry of Gold Nanoparticles Determines the Biocorona Composition Impacting Cellular Uptake, Toxicity and Gene Expression Profiles in Human Endothelial Cells." Nanotoxicology 11 (4), 507-519. doi: 10.1080/17435390.2017.1314036

Chang, P. K., A. Khatchadourian, R. A. McKinney, and D. Maysinger. 2015. “Docosahexaenoic acid (DHA): A Modulator of Microglia Activity and Dendritic Spine Morphology.” Journal of Neuroinflammation 12: 34. doi: 10.1186/s12974015-0244-5

Cheng, Y., Q. Dai, R. A. Morshed, X. B. Fan, M. L. Wegscheid, D. A. Wainwright, Y. Han, et al. 2014. "Blood-Brain Barrier Permeable Gold Nanoparticles: An 
Efficient Delivery Platform for Enhanced Malignant Glioma Therapy and Imaging.” Small 10 (24): 5137-5150.

Cole, L.E., R. D. Ross, J. M. R. Tilley, T. Vargo-Gogola, and R. K. Roeder. 2015. “Gold Nanoparticles As Contrast Agents in X-Ray Imaging and Computed Tomography." Nanomedicine 10 (2) 321-341.

Colgan, L.A., and R. Yasuda. 2014. "Plasticity of Dendritic Spines: Subcompartmentalization of Signaling." Annual Review of Physiology 76: 365385.

Coluccia, D., C. A. Figueiredo, M. Y. Wu, A. N. Riemenschneider, R. Diaz, A. Luck, C. Smith, et al. 2018. "Enhancing Glioblastoma Treatment Using Cisplatin-GoldNanoparticle Conjugates and Targeted Delivery with Magnetic ResonanceGuided Focused Ultrasound." Nanomedicine 14 (4): 1137-1148. doi: 10.1016/j.nano.2018.01.021

Conrad, C. D., K. J. McLaughlin, T. N. Huynh, M. El-Ashmawy, and M. Sparks. 2012. “Chronic Stress and a Cyclic Regimen of Estradiol Administration Separately Facilitate Spatial Memory: Relationship with Hippocampal CA1 Spine Density and Dendritic Complexity.” Behavioral Neuroscience 126 (1): 142-146. doi: $10.1037 / \mathrm{a} 0025770$

Daniel, M. C., and D. Astruc. 2004. “Gold Nanoparticles: Assembly, Supramolecular Chemistry, Quantum-Size-Related Properties, and Applications toward Biology, Catalysis, and Nanotechnology." Chemical Reviews 104 (1): 293-346. doi: $10.1021 / \mathrm{cr} 030698+$ 
De Paola, V., S. Arber, and P. Caroni. 2003. “AMPA Receptors Regulate Dynamic Equilibrium of Presynaptic Terminals in Mature Hippocampal Networks.” Nature Neuroscience 6 (5): 491-500.

Dobrovolskaia, M.A., M. Shurin, M., and A. A. Shvedova. 2016. “Current Understanding of Interactions Between Nanoparticles and the Immune System.” Toxicology and Applied Pharmacology 299: 78-89.

Dreaden, E. C., A. M. Alkilany, X. Huang, C. J. Murphy, and M. A. El-Sayed. 2012. “The Golden Age: Gold Nanoparticles for Biomedicine.” Chemical Society Reviews 41 (7): 2740-79

Dykman, L. A., and N. G. Khlebtsov. 2014. "Uptake of Engineered Gold Nanoparticles into Mammalian Cells." Chemical Reviews 114 (2): 1258-1288. doi: $10.1021 / \operatorname{cr} 300441 \mathrm{a}$

Ebrahimi, S., and S. Okabe. 2014. "Structural Dynamics of Dendritic Spines: Molecular Composition, Geometry and Functional Regulation." Biochimica et Biophysica Acta (BBA) - Biomembranes 1838 (10): 2391-2398.

Eilam-Stock, T., P. Serrano, M. Frankfurt, and V. Luine. 2012. "Bisphenol-A Impairs Memory and Reduces Dendritic Spine Density in Adult Male Rats.” Behavioral Neuroscience 126 (1): 175-185. doi: 10.1037/a0025959

Eom, K., S. Hwang, S. Yun, K. M. Byun, S. B. Jun, and S. J. Kim. 2017. "Photothermal Activation of Astrocyte Cells Using Localized Surface Plasmon Resonance of Gold Nanorods." Journal of Biophotonics 10 (4): 486-493. doi:

10.1002/jbio. 201600280 
Falagan-Lotsch, P., E. M. Grzincic, C. J. Murphy. 2016. “One Low-Dose Exposure of Gold Nanoparticles Induces Long-Term Changes in Human Cells.” Proceedings of the National Academy of Sciences of the United States of America 113 (47): 13318-13323. doi: 10.1073/pnas.1616400113

Fischer, M., S. Kaech, D. Knutti, and A. Matus. 1998. "Rapid Actin-Based Plasticity in Dendritic Spines.” Neuron 20 (5): 847-854.

Fratoddi, I., I. Venditti, C. Cametti, and M. V. Russo. 2015. "How Toxic Are Gold Nanoparticles? The State-of-the-art." Nano Research 8 (6): 1771-1799.

Freese, C., L. Anspach, R. C. Deller, S. J. Richards, M. I. Gibson, C. J. Kirkpatrick, and R. E. Unger. 2017. “Gold Nanoparticle Interactions with Endothelial Cells Cultured under Physiological Conditions.” Biomaterials Science 5 (4): 707-717. doi: $10.1039 / \mathrm{c} 6 \mathrm{bm} 00853 \mathrm{~d}$

Gahwiler, B. H. 1981. "Morphological Differentiation of Nerve Cells in Thin Organotypic Cultures Derived from Rat Hippocampus and Cerebellum.” Proceedings of the Royal Society of London. Series B, Biological Sciences 211 (1184): 287-290. doi: 10.1098/rspb.1981.0007Gahwiler, B. H. 1981. “Organotypic Monolayer Cultures of Nervous Tissue.” Journal of Neuroscience Methods 4 (4): 329-342. doi: 10.1016/0165-0270(81)90003-0

Gahwiler, B. H., M. Capogna, D. Debanne, R. A. McKinney, and S. M. Thompson. 1997. “Organotypic Slice Cultures: A Technique Has Come of Age.” Trends in Neurosciences 20 (10): 471-477. 
Glaser, T., I. Han, L. Wu, and X. Zeng. 2017. “Targeted Nanotechnology in Glioblastoma Multiforme." Frontiers in Pharmacology 8: 166. doi: 10.3389/fphar.2017.00166

Goo, M. S., L. Sancho, N. Slepak, D. Boassa, T. J. Deerinck, M. H. Ellisman, B. L. Bloodgood, et al. 2017. “Activity-Dependent Trafficking of Lysosomes in Dendrites and Dendritic Spines.” Journal of Cell Biology 216 (8):2499-2513. doi: $10.1083 /$ jcb. 201704068

Gray, M.A., C. H. Choy, R. M. Dayam, E. Ospina-Escobar, A. Somerville, X. Xiao, S. M. Ferguson, and R. J. Botelho. 2016. "Phagocytosis Enhances Lysosomal and Bactericidal Properties by Activating the Transcription Factor TFEB." Current Biology 26 (15): 1955-1964.

Grutzendler, J., N. Kasthuri, and W. B. Gan. 2002. "Long-Term Dendritic Spine Stability in the Adult Cortex." Nature 420: 812-816.

Gunduz, N., H. Ceylan, M. OGuler, and A. B. Tekinay. 2017. "Intracellular Accumulation of Gold Nanoparticles Leads to Inhibition of Macropinocytosis to Reduce the Endoplasmic Reticulum Stress." Scientific Reports 7: 40493.

Haber, M., L. Zhou, and K. K. Murai. 2006. “Cooperative Astrocyte and Dendritic Spine Dynamics at Hippocampal Excitatory Synapses.” Journal of Neuroscience 26 (35): 8881-8891. doi: 10.1523/JNEUROSCI.1302-06.2006

Hamouda, R., F. Bertorelle, D. Rayane, R. Antoine, M. Broyer, and P. Dugourd. 2013. “Glutathione Capped Gold AuN(SG)M Clusters Studied by Isotope-Resolved Mass Spectrometry.” International Journal of Mass Spectrometry 335: 1-6. doi: 10.1016/j.ijms.2012.10.008 
Han, G., P. Ghosh, and V. M. Rotello. 2007. "Functionalized Gold Nanoparticles for Drug Delivery." Nanomedicine (London) 2 (1): 113-123.

Holtmaat, A.J., J. T. Trachtenberg, L. Wilbrecht, G. M. Shepherd, X. Zhang, G. W. Knott, and K. Svoboda. 2005. "Transient and Persistent Dendritic Spines in the Neocortex In Vivo.” Neuron 45 (2): 279-91.

Hotulainen, P. and C. C. Hoogenraad. 2010. “Actin in Dendritic Spines: Connecting Dynamics to Function.” Journal of Cell Biology 189 (4): 619-629.

Huang, X., I. H. El-Sayed, W. Qian, and M. A. El-Sayed. 2006. “Cancer Cell Imaging and Photothermal Therapy in the Near-Infrared Region by Using Gold Nanorods." Journal of the American Chemical Society 128 (6): 2115-2120. doi: $10.1021 / \mathrm{ja} 057254 \mathrm{a}$

Humpel, C. 2015. “Organotypic Brain Slice Cultures: A Review.” Neuroscience 305: 8698. doi: 10.1016/j.neuroscience.2015.07.086

Hussein, E. A., M. M. Zagho, G. K. Nasrallah, and A. A. Elzatahry. 2018. "Recent Advances in Functional Nanostructures as Cancer Photothermal Therapy." International Journal of Nanomedicine 13: 2897-2906. doi: 10.2147/IJN.S161031

Hutter, E., S. Boridy, S. Labrecque, M. Lalancette-Hebert, J. Kriz, F. M. Winnik, and D. Maysinger. 2010. "Microglial Response to Gold Nanoparticles." ACS Nano 4 (5): 2595-2606.

Jedlicka, P., A. Vlachos, S. W. Schwarzacher, and T. Deller. 2008. "A Role for the Spine Apparatus in LTP and Spatial Learning." Behavioural Brain Research 192 (1): 12-19. doi: 10.1016/j.bbr.2008.02.033 
Jiang, D.-E., S. H. Overbury, and S. Dai. 2013. "Structure of $\mathrm{Au}_{15}(\mathrm{SR})_{13}$ and Its

Implication for the Origin of the Nucleus in Thiolated Gold Nanoclusters."

Journal of the American Chemical Society 135 (24): 8786-8789. doi:

$10.1021 / \mathrm{ja} 402680 \mathrm{c}$

Jiang, P. D. and N. Mizushima. 2014. “Autophagy and Human Diseases.” Cell Research 24 (1): 69-79.

Kang, X., H. Chong, and M. Zhu. 2018. " $\mathrm{Au}_{25}(\mathrm{SR})_{18}$ : The Captain of the Great Nanocluster Ship.” Nanoscale 10 (23): 10758-10834. doi: 10.1039/c8nr02973c

Kuncic, Z., and S. Lacombe. 2018. "Nanoparticle Radio-Enhancement: Principles, Progress and Application to Cancer Treatment." Physics in Medicine and Biology 63 (2): 02tr01. doi: 10.1088/1361-6560/aa99ce

Lavoie-Cardinal, F., C. Salesse, E. Bergeron, M. Meunier, and P. De Koninck. 2016. "Gold Nanoparticle-Assisted All Optical Localized Stimulation and monitoring of $\mathrm{Ca}(2)(+)$ signaling in neurons." Science Reports 6, 20619. doi: 10.1038/srep20619 Leng, F., F. Liu, Y. Yang, Y. Wu, and W. Tian, W. 2018. "Strategies on Nanodiagnostics and Nanotherapies of the Three Common Cancers." Nanomaterials (Basel) 8 (4): 202. doi: 10.3390/nano8040202

Leuner, B., J. Falduto, and T. J. Shors. 2003. “Associative Memory Formation Increases the Observation of Dendritic Spines in the Hippocampus.” Journal of Neuroscience 23 (2): 659-665. doi: 10.1523/JNEUROSCI.23-02-00659.2003 Li, G., D.-E. Jiang, S. Kumar, Y. Chen, and R. Jin. 2014. "Size Dependence of Atomically Precise Gold Nanoclusters in Chemoselective Hydrogenation and Active Site Structure.” ACS Catalysis 4 (8): 2463-2469. doi: 10.1021/cs500533h 
Li, J.J., D. Hartono, C. N. Ong, B. H. Bay, L. Y. L. and Yung. 2010. “Autophagy and Oxidative Stress Associated with Gold Nanoparticles.” Biomaterials 31 (23): $5996-6003$.

Li, W.J., P. Zhan, E. De Clercq, H. X. Lou, and X. Y. Liu. 2013. "Current Drug Research on PEGylation with Small Molecular Agents." Progress in Polymer Science 38 (3-4): 421-444.

Lim, C.-Y., and R. Zoncu. 2016. "The Lysosome as a Command-and-Control Center for Cellular Metabolism." Journal of Cell Biology 214 (6): 653. doi: $10.1083 /$ jcb.201607005

Liu, H.-L., J. Cao, S. Hanif, C. Yuan, J. Pang, R. Levicky, X.-H. Xia, et al. 2017. "SizeControllable Gold Nanopores with High SERS Activity." Analytical Chemistry 89 (19): 10407-10413. doi: 10.1021/acs.analchem.7b02410

Liu, M.M., Q. Li, L. Liang, J. Li, K. Wang, J. J. Li, M. Lv, et al. 2017. "Real-Time Visualization of Clustering and Intracellular Transport of Gold Nanoparticles by Correlative Imaging.” Nature Communications 8: 15646.

Ma, X.W., Y. Y. Wu, S. B. Jin, Y. Tian, X. N. Zhang, Y. L. Zhao, L. Yu, and X. J. Liang. 2011. "Gold Nanoparticles Induce Autophagosome Accumulation through SizeDependent Nanoparticle Uptake and Lysosome Impairment.” ACS Nano 5 (11): 8629-8639.

Ma, Z., K. Han, X. Dai, and H. Han. 2018. "Precisely Striking Tumors without Adjacent Normal Tissue Damage via Mitochondria-Templated Accumulation." ACS Nano. doi: $10.1021 / a c s n a n o .8 b 03212$ 
Maysinger, D., A. Moquin, J. Choi, M. Kodiha, and U. Stochaj, U. 2018. “Gold Nanourchins and Celastrol Reorganize the Nucleo- and Cytoskeleton of Glioblastoma Cells.” Nanoscale 10 (4): 1716-1726. doi: 10.1039/c7nr07833a.

Maysinger, D., J. Ji, E. Hutter, and E. Cooper. 2015. "Nanoparticle-Based and Bioengineered Probes and Sensors to Detect Physiological and Pathological Biomarkers in Neural Cells." Frontiers in Neuroscience 9, 480. doi: $10.3389 /$ fnins. 2015.00480

Maysinger, D., J. Ji, A. Moquin, S. Hossain, M. A. Hancock, I. Zhang, P. K. Y. Chang, et al. 2018. "Dendritic Polyglycerol Sulfates in the Prevention of Synaptic Loss and Mechanism of Action on Glia." ACS Chemical Neuroscience 9 (2): 260-271.

McKinney, R.A., 2010. "Excitatory Amino Acid Involvement in Dendritic Spine Formation, Maintenance and Remodelling.” The Journal of Physiology 588 (1): $107-116$.

Meola, A., J. Rao, N. Chaudhary, M. Sharma, and S. D. Chang. 2018. "Gold Nanoparticles for Brain Tumor Imaging: A Systematic Review." Frontiers in Neurology 9 (328). doi: 10.3389/fneur.2018.00328

Mikhaylova, M., J. Bar, B. Van Bommel, P. Schatzle, P. Yuanxiang, R. Raman, J. Hradsky, et al. 2018. “Caldendrin Directly Couples Postsynaptic Calcium Signals to Actin Remodeling in Dendritic Spines.” Neuron 97 (5): 1110-1125.

Milatovic, D., T. J. Montine, S. Zaja-Milatovic, J. L. Madison, A. B. Bowman, and M. Aschner. 2010. "Morphometric analysis in neurodegenerative disorders." Current Protocols in Toxicology Chapter 12, Unit 12: 16. 
Moser, M. B., M. Trommald, and P. Andersen. 1994. “An Increase in Dendritic Spine Density on Hippocampal CA1 Pyramidal Cells Following Spatial Learning in Adult Rats Suggests the Formation of New Synapses." Proceedings of the National Academy of Sciences of the United States of America 91 (26): 1267312675. doi: 10.1073/pnas.91.26.12673

Neibert, K.D. and D. Maysinger. 2012. "Mechanisms of Cellular Adaptation to Quantum Dots - The Role of Glutathione and Transcription Factor EB." Nanotoxicology 6 (3): $249-262$.

Neuschmelting, V., S. Harmsen, N. Beziere, H. Lockau, H. T. Hsu, R. Huang, D. Razansky, et al. 2018. “Dual-Modality Surface-Enhanced Resonance Raman Scattering and Multispectral Optoacoustic Tomography Nanoparticle Approach for Brain Tumor Delineation.” Small 14 (23): e1800740. doi: 10.1002/smll.201800740

Padamsey, Z., L. McGuinness, S. J. Bardo, M. Reinhart, R. Tong, A. Hedegaard, M. L. Hart, et al. 2017. "Activity-Dependent Exocytosis of Lysosomes Regulates the Structural Plasticity of Dendritic Spines.” Neuron 93 (1): 132-146. doi: 10.1016/j.neuron.2016.11.013

Pan, Y., A. Leifert, D. Ruau, S. Neuss, J. Bornemann, G. Schmid, W. Brandau, U. Simon, and W. Jahnen-Dechent. 2009. “Gold Nanoparticles of Diameter 1.4 nm Trigger Necrosis by Oxidative Stress and Mitochondrial Damage.” Small 5 (18): 20672076. 
Pan, Y., S. Neuss, A. Leifert, M. Fischler, F. Wen, U. Simon, G. Schmid, W. Brandau, and W. Jahnen-Dechent. 2007. "Size-Dependent Cytotoxicity Of Gold Nanoparticles." Small 3 (11): 1941-1949.

Pastore, N., O. A. Brady, H. I. Diab, J. A. Martina, L. Sun, T. Huynh, J. A. Lim, et al. 2016. "TFEB and TFE3 Cooperate in the Regulation of the Innate Immune Response in Activated Macrophages." Autophagy, 12 (8): 1240-1258.

Penzes, P., M. E. Cahill, K. A. Jones, J. E. Vanleeuwen, and K. M. Woolfrey. 2011. “Dendritic Spine Pathology in Neuropsychiatric Disorders.” Nature Neuroscience 14 (3): 285-293.

Perez-Alvarez, A., M. Navarrete, A. Covelo, E. D. Martin, and A. Araque. 2014. "Structural and Functional Plasticity of Astrocyte Processes and Dendritic Spine Interactions." Journal of Neuroscience 34 (38): 12738-12744. doi: 10.1523/JNEUROSCI.2401-14.2014

Polavarapu, L., M. Manna, and Q. H. Xu. 2011. "Biocompatible Glutathione Capped Gold Clusters As One- and Two-Photon Excitation Fluorescence Contrast Agents for Live Cells Imaging." Nanoscale 3 (2): 429-434.

Qiu, Y., Y. Liu, L. M. Wang, L. G. Xu, R. Bai, Y. L. Ji, X. C. Wu, Y. L. Zhao, Y. F. Li, and C. Y. Chen. 2010. "Surface Chemistry and Aspect Ratio Mediated Cellular Uptake of Au Nanorods.” Biomaterials 31 (30): 7606-7619.

Raben, N. and R. Puertollano. 2016. “TFEB and TFE3: Linking Lysosomes to Cellular Adaptation to Stress." Annual Review of Cell and Developmental Biology Vol 32 32: $255-278$. 
Raliya, R., D. Saha, T. S. Chadha, B. Raman, and P. Biswas. 2017. "Non-Invasive Aerosol Delivery and Transport of Gold Nanoparticles to the Brain." Scientific Reports 7: 44718. doi: 10.1038/srep44718

Rayavarapu, R.G., W. Petersen, L. Hartsuiker, P. Chin, H. Janssen, F. W. B. Van Leeuwen, C. Otto, S. Manohar, and T. G. Van Leeuwen. 2010. “In Vitro Toxicity Studies of Polymer-Coated Gold Nanorods." Nanotechnology 21 (14): 145101.

Richards, D.A., J. M. Mateos, S. Hugel, V. De Paola, P. Caroni, B. H. Gahwiler, and R. A. McKinney. 2005. "Glutamate Induces the Rapid Formation of Spine Head Protrusions in Hippocampal Slice Cultures." Proceedings of the National Academy of Sciences of the United States of America 102 (17): 6166-6171.

Rosa, S., C. Connolly, G. Schettino, K. T. Butterworth, and K. M. Prise. 2017. "Biological Mechanisms of Gold Nanoparticle Radiosensitization.” Cancer Nanotechnology 8 (1): 2. doi: 10.1186/s12645-017-0026-0

Ruff, J., S. Hüwel, M. J. Kogan, U. Simon, and H. J. Galla. 2017. “The Effects of Gold Nanoparticles Functionalized with ß-Amyloid Specific Peptides on an In Vitro Model of Blood-Brain Barrier." Nanomedicine 13 (5): 1645-1652. doi: 10.1016/j.nano.2017.02.013

Russier-Antoine, I., F. Bertorelle, M. Vojkovic, D. Rayane, E. Salmon, C. Jonin, P. Dugourd, R. Antoine, and P. F. Brevet. 2014. "Non-Linear Optical Properties of Gold Quantum Clusters. The Smaller the Better.” Nanoscale 6 (22): 1357213578. 
Saha, K., S. S. Agasti, C. Kim, X. Li, and V. M. Rotello. 2012. "Gold Nanoparticles in Chemical and Biological Sensing." Chemical Reviews 112 (5): 2739-2779. doi: $10.1021 /$ cr2001178

Salinas, K., Z. Kereselidze, F. DeLuna, X. G. Peralta, and F. Santamaria. 2014.

"Transient Extracellular Application of Gold Nanostars Increases Hippocampal Neuronal Activity." Journal of Nanobiotechnology 12: 31. doi: 10.1186/s12951014-0031-y

Sau, T.K. and C. J. Murphy. 2004. "Seeded High Yield Synthesis of Short Au Nanorods in Aqueous Solution." Langmuir 20 (15): 6414-6420.

Savchenko, A., G. B. Braun, and E. Molokanova. 2016. "Nanostructured Antagonist of Extrasynaptic NMDA Receptors.” Nano Letters 16 (9): 5495-5502.

Schulz, F., D. Lutz, N. Rusche, N. G. Bastus, M. Stieben, M. Holtig, F. Gruner, et al. 2013. "Gold Nanoparticles Functionalized with a Fragment of the Neural Cell Adhesion Molecule L1 Stimulate L1-Mediated Functions." Nanoscale 5 (21): 10605-10617. doi: 10.1039/c3nr02707d

Segal, M. 2001. "Rapid Plasticity of Dendritic Spine: Hints to Possible Functions?" Progress in Neurobiology 63 (1): 61-70.

Shukla, R., V. Bansal, M. Chaudhary, A. Basu, R. R. Bhonde, and M. Sastry. 2005. "Biocompatibility of Gold Nanoparticles and their Endocytotic Fate Inside the Cellular Compartment: A Microscopic Overview.” Langmuir 21 (23) : 10644 10654.

Soleilhac, A., F. Bertorelle, C. Comby-Zerbino, F. Chirot, N. Calin, P. Dugourd, and R. Antoine. 2017. "Size Characterization of Glutathione-Protected Gold 
Nanoclusters in the Solid, Liquid and Gas Phases." Journal of Physical Chemistry C 121 (49): 27733-27740.

Song, W.S., S. S. Lee, M. Savini, L. Popp, V. L. Colvin, and L. Segatori. 2014. “Ceria Nanoparticles Stabilized by Organic Surface Coatings Activate the LysosomeAutophagy System and Enhance Autophagic Clearance." ACS Nano 8 (10): 10328-10342.

Song, W.S., L. Popp, J. Yang, A. Kumar, V. S. Gangoli, and L. Segatori. 2015. "The Autophagic Response to Polystyrene Nanoparticles Is Mediated by Transcription Factor EB and Depends on Surface Charge." Journal of Nanobiotechnology 13: 87.

Stern, S. T., P. P. Adiseshaiah, and R. M. Crist. 2012. “Autophagy and Lysosomal Dysfunction As Emerging Mechanisms of Nanomaterial Toxicity." Particle and Fibre Toxicology 9: 20.

Sung, W., and J. Schuemann. 2018. "Energy Optimization in Gold Nanoparticle Enhanced Radiation Therapy." Physics in Medicine and Biology. Accepted Manuscript online doi: 10.1088/1361-6560/aacab6

Talamini, L., M. B. Violatto, Q. Cai, M. P. Monopoli, K. Kantner, Ž. Krpetić, A. PerezPotti, et al. 2017. "Influence of Size and Shape on the Anatomical Distribution of Endotoxin-Free Gold Nanoparticles." ACS Nano 11 (6): 5519-5529. doi: 10.1021/acsnano.7b00497

Tay, C.Y., Y. Yu, Y., M. I. Setyawati, J. P. Xie, and D. T. Leong. 2014. "Presentation Matters: Identity of Gold Nanocluster Capping Agent Governs Intracellular Uptake and Cell Metabolism.” Nano Research 7 (6): 805-815. 
Tsoli, M., H. Kuhn, W. Brandau, H. Esche, and G. Schmid. 2005. "Cellular Uptake and Toxicity of Au55 Clusters." Small 1 (8-9): 841-844.

Verbich, D., G. A. Prenosil, P. K.-Y. Chang, K. K. Murai, and R. A. McKinney. 2012. “Glial Glutamate Transport Modulates Dendritic Spine Head Protrusions in the Hippocampus.” Glia 60 (7): 1067-1077. doi: 10.1002/glia.22335

Wang, J. Y., J. Chen, J. Yang, H. Wang, X. Shen, Y. M. Sun, M. Guo, and X. D. Zhang. 2016. "Effects of Surface Charges of Gold Nanoclusters on Long-Term In Vivo Biodistribution, Toxicity, and Cancer Radiation Therapy.” International Journal of Nanomedicine 11: 3475-3485. doi: 10.2147/ijn.s106073

Wang, J., Y. F. Li, C. Z. Huang, and T. Wu. 2008a. "Rapid and Selective Detection of Cysteine Based on its Induced Aggregates of Cetyltrimethylammonium Bromide Capped Gold Nanoparticles." Analytica Chimica Acta 626 (1): 37-43.

Wang, S.G., W. T. Lu, O. Tovmachenko, U. S. Rai, H. T. Yu, and P. C. Ray. 2008b. "Challenge in Understanding Size and Shape Dependent Toxicity of Gold Nanomaterials in Human Skin Keratinocytes." Chemical Physics Letters 463 (13): $145-149$.

Wang, T.Y., D. Halaney, D. Ho, M. D. Feldman, and T. E. Milner. 2013. "Two-Photon Luminescence Properties of Gold Nanorods.” Biomedical Optics Express 4 (4): $584-595$.

Xue, Y., X. Li, H. Li, and W. Zhang. 2014. “Quantifying thiol-gold interactions Towards the Efficient Strength Control." Nature Communications 5: 4348. doi:10.1038/ncomms5348 
Yah, C.S. 2013. "The Toxicity of Gold Nanoparticles in Relation to their Physiochemical Properties." Biomedical Research-India 24 (3): 400-413.

Yu, K.F., K. L. Kelly, N. Sakai, and T. Tatsuma. 2008. "Morphologies and Surface Plasmon Resonance Properties of Monodisperse Bumpy Gold Nanoparticles.” Langmuir 24 (11): 5849-5854.

Zhang, X.D., Z. T. Luo, J. Chen, S. S. Song, X. Yuan, X. Shen, H. Wang, et al. 2015. "Ultrasmall Glutathione-Protected Gold Nanoclusters as Next Generation Radiotherapy Sensitizers with High Tumor Uptake and High Renal Clearance. Scientific Reports 5: 8669.

Zhang, X. D., D. Wu, X. Shen, P. X. Liu, F. Y. Fan, and S. J. Fan. 2012. “In Vivo Renal Clearance, Biodistribution, Toxicity of Gold Nanoclusters.” Biomaterials 33 (18): $4628-4638$.

Zhu, M., C. M. Aikens, F. J. Hollander, G. C. Schatz, and R. Jin. 2008. "Correlating the Crystal Structure of a Thiol-Protected $\mathrm{Au}_{25}$ Cluster and Optical Properties.’ Journal of the American Chemical Society 130 (18): 5883-5885. doi: 10.1021/ja801173r

Zuo, Y., A. Lin, P. Chang, and W. B. Gan. 2005. "Development of Long-Term Dendritic Spine Stability in Diverse Regions of Cerebral Cortex." Neuron 46 (2): 181-189. 


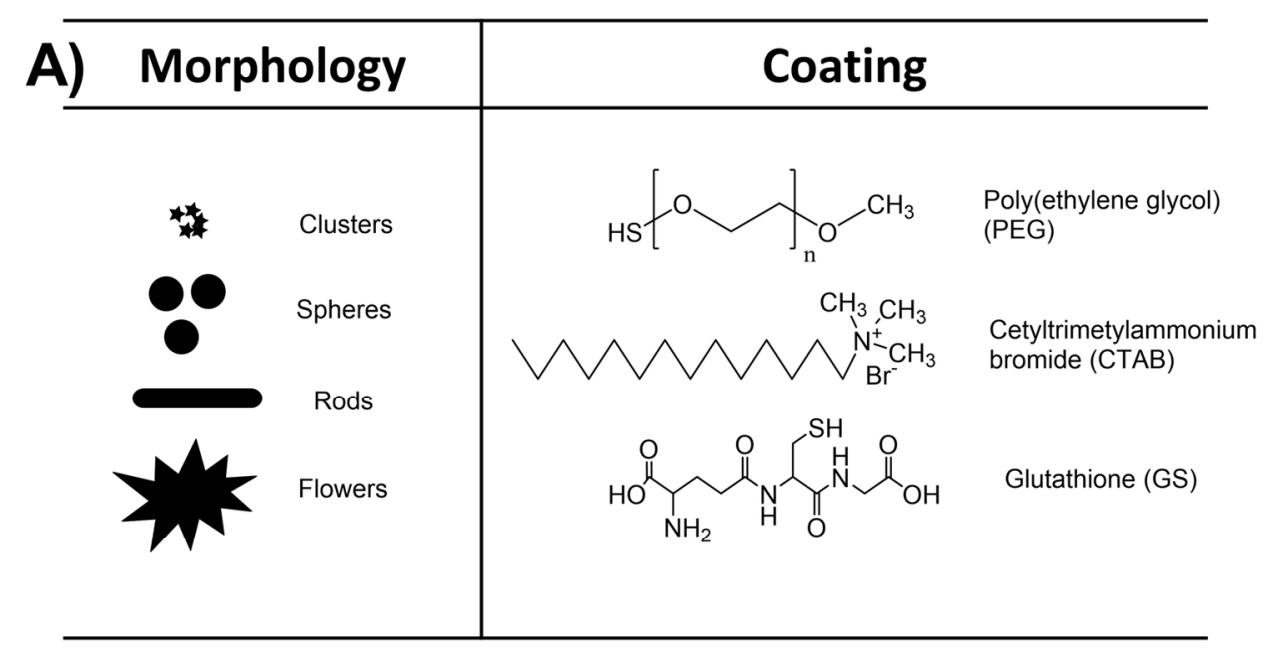

\section{B)}

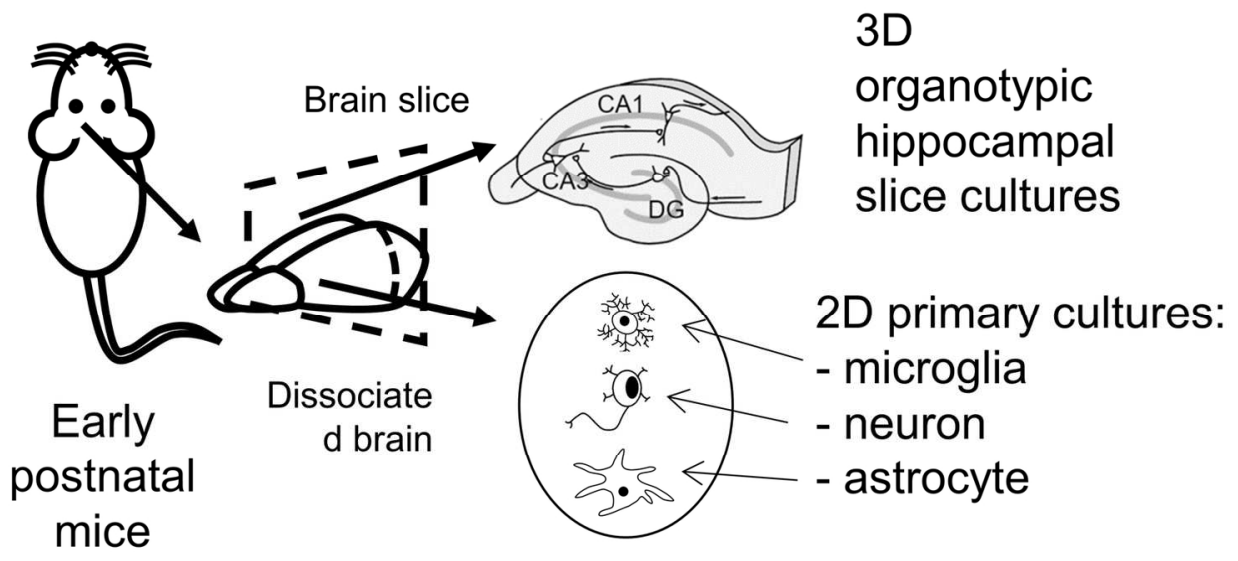

Figure 1) Methodological approach and AuNP shape and coating. A) A graphical table illustrating types of AuNP morphology and surface functionalization on the AuNPs. B) Schematic of 3D organotypic hippocampal slice culture and 2D dissociated primary culture models used in this study.

$150 \times 160 \mathrm{~mm}(300 \times 300 \mathrm{DPI})$ 
Figure 2) Characteristics of AuNP. (A) Transmission electron microscopic (TEM) images of the AuNS, AuNR, and AuNF. Scale bars represent $100 \mathrm{~nm}$ for gold nanospheres, nanorods, and nanoflowers. (B) UV-Vis absorption spectra of the same nanoparticles in water. (C) Asymmetric Flow Field-Flow Fractionation (AF4) fractograms obtained using the same separation method for the three types of nanoparticles. The black line represents the normalized absorption measured at $520 \mathrm{~nm}$ reported on the left y-axis as a function of elution time. The red dots for AuNS and AuNR represent the hydrodynamic radii measure by inline dynamic light scattering detector at $90^{\circ}$, the black dots represent the root-mean square (rms) radii of the nanoparticles measured by the multiangle light (MALS) scattering detector. The channel was fitted with a regenerated cellulose membrane (10 kDa cut-off), a $350 \mu \mathrm{m}$ high channel, and the running solvent was filtered phosphate buffer (10 mM, pH 7.0).

$189 \times 164 \mathrm{~mm}(300 \times 300 \mathrm{DPI})$ 
A)

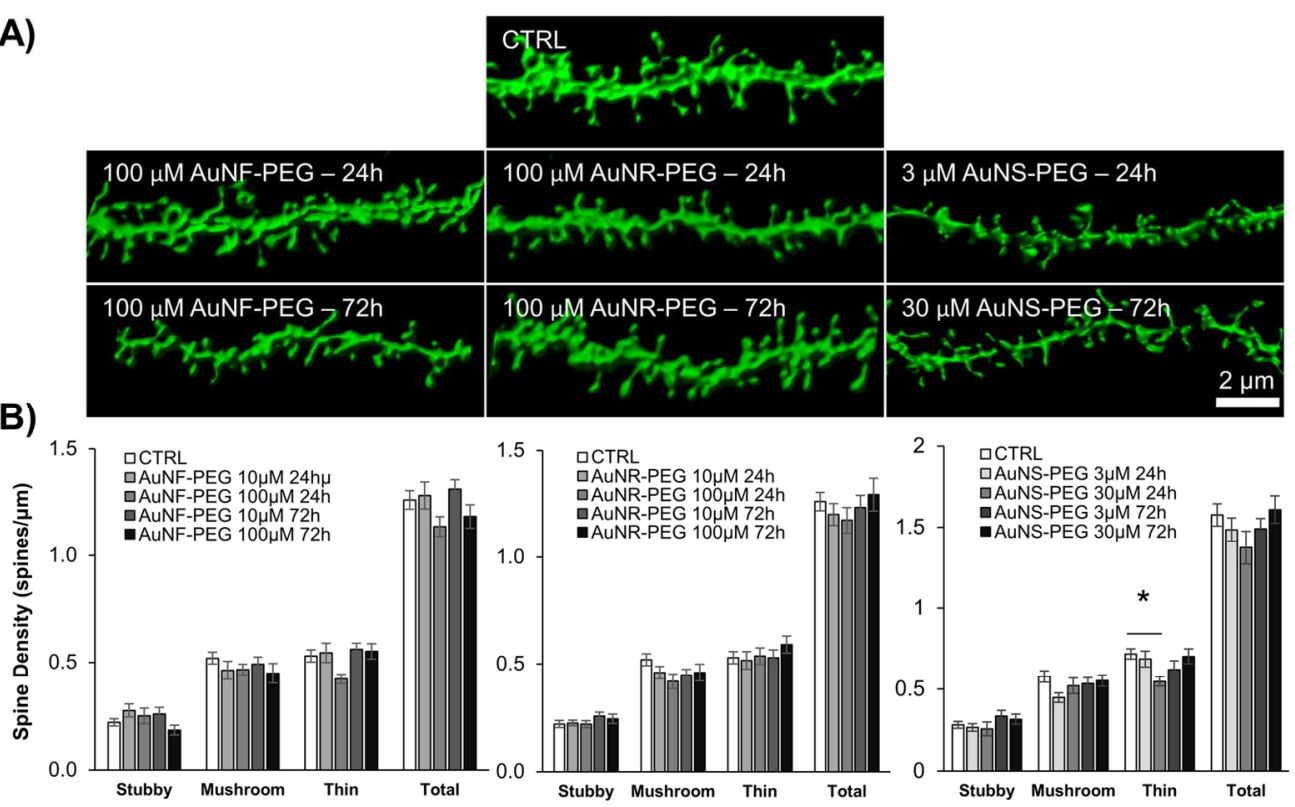

Figure 3) Effects of PEG-coated AuNP on hippocampal spine density. A) Representative photomicrographs of hippocampal dendritic spines exposed to $(10,100 \mu \mathrm{M})$ AuNP-flowers-PEG, $(10,100 \mu \mathrm{M})$ AuNP-rods-PEG, and $(3,30 \mu \mathrm{M})$ AuNP-spheres-PEG for 24 hours and 72 hours from independent experiments. There was a significant reduction in both thin and total spine density after treatment with $30 \mu \mathrm{M}$ AuNP-spheres-PEG for

24 hours compared to control. Scale bars represent $2 \mu \mathrm{m}$. B) Quantification of spine subtype and total density. * denotes $\mathrm{p}<0.05, \mathrm{n}>8$ dendrites from at least 3 independent cultures per condition.

$136 \times 84 \mathrm{~mm}(300 \times 300 \mathrm{DPI})$ 

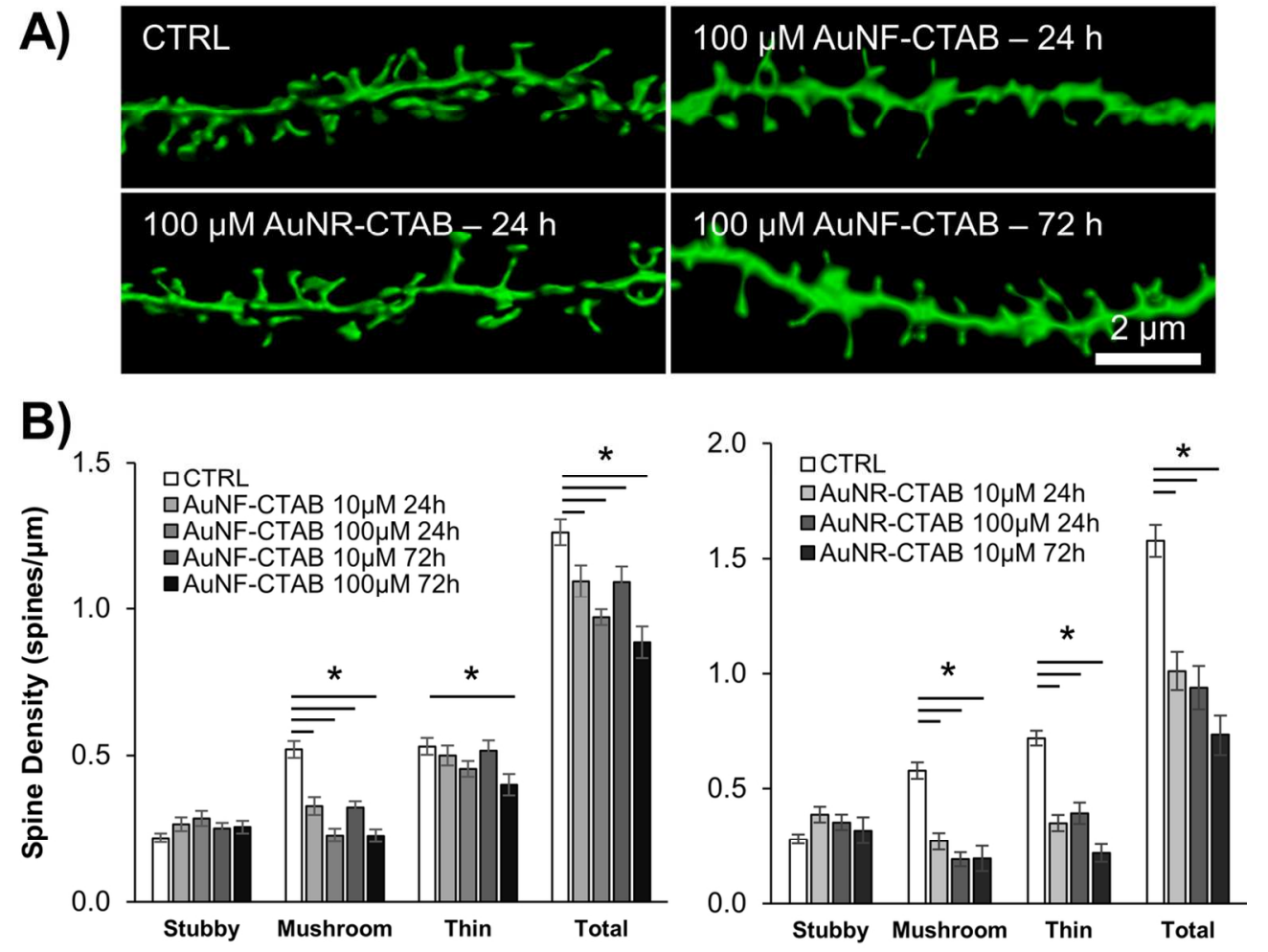

Figure 4) Effects of CTAB-coated AuNP on hippocampal spine density. A) Representative photomicrographs of hippocampal dendritic spines exposed to AuNP-flowers-PEG, AuNP-rods-PEG, and AuNP-spheres-PEG for 24 hours and 72 hours. The results presented in panels A and B are from independent experiments at 24 hours and 72 hours. Scale bars represent $2 \mu \mathrm{m}$. B) Quantification of spine subtype and total density. Both $10 \mu \mathrm{M}$ and $100 \mu \mathrm{M}$ AuNP-flowers-CTAB treatment significantly lowered mushroom spine density compared to control after both 24 hours, and 72 hours. AuNP-rods-CTAB treatment significantly reduced mushroom, thin, and total spine density after 24 hours $(10$ and $100 \mu \mathrm{M})$, and 72 hours $(10 \mu \mathrm{M})$ compared to controls. $100 \mu \mathrm{M}$ AuNP-rods-CTAB treatment for 72 hours caused widespread cell death which destroyed most of the hippocampal neurons, the spine density could not be determined. * denotes $p<0.05, n>12$ dendrites from at least 3 independent cultures per condition.

$120 \times 93 \mathrm{~mm}(300 \times 300$ DPI $)$ 


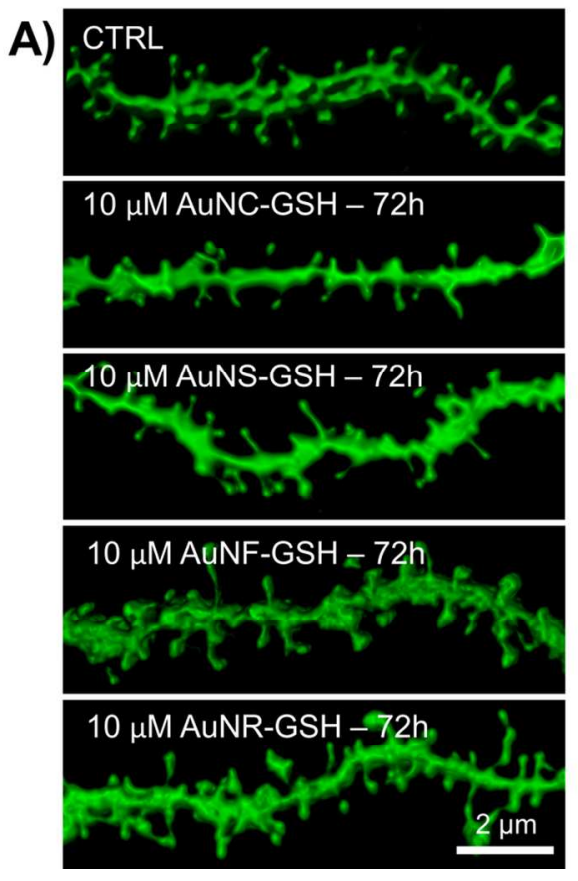

B)

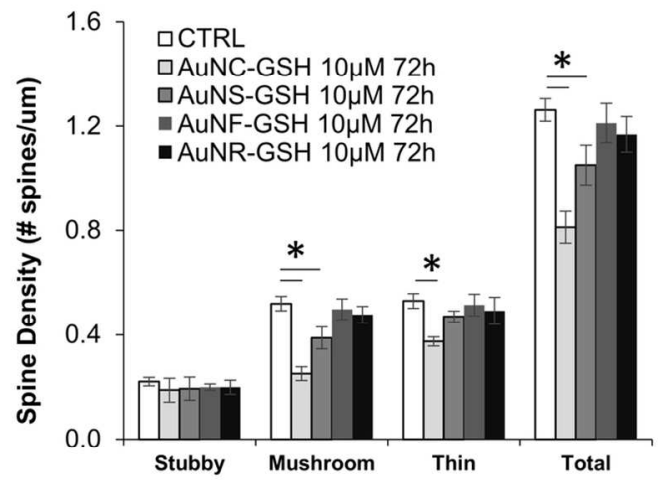

Figure 5) Effects of GSH-coated AuNP on hippocampal spine density. A) Representative photomicrographs of hippocampal dendritic spines exposed to $10 \mu \mathrm{M}$ AuNC-GSH, AuNS-GSH, AuNF-GSH, and AuNR-GSH for $72 \mathrm{~h}$. While both AuNC-GSH and AuNS-GSH, caused a significant reduction in spine density, AuNC-GSH proved more deleterious and caused the greatest loss in both mushroom and total spine density. B) Quantification of spine subtype and total density. $n>7$ dendrites from at least 2 independent cultures per condition. $*$ denotes $\mathrm{p}<0.05$

$117 \times 78 \mathrm{~mm}(300 \times 300 \mathrm{DPI})$ 


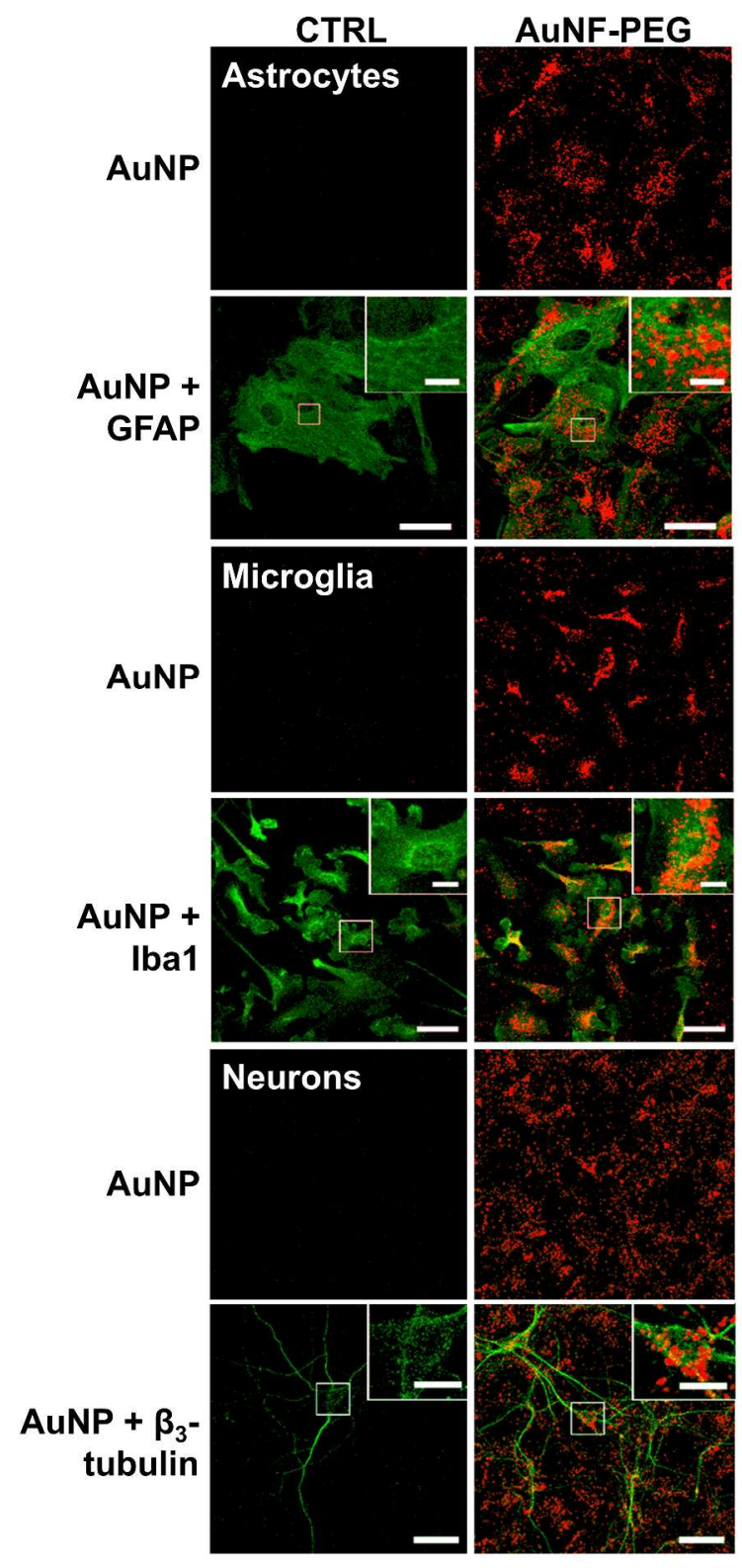

Figure 6) AuNF-PEG in primary neural cells. Primary astrocyte, microglia, and neuronal cultures were treated with $100 \mu \mathrm{M}$ AuNF-PEG for 18 hours. Astrocytes were immunolabeled with GFAP, microglia were labeled with Iba-1, and neurons with $\beta 3$-tubulin. AuNPs were excited at $720 \mathrm{~nm}$ using two-photon excitation microscopy using light at $720 \mathrm{~nm}$ and imaged using a $63 \mathrm{x}$ objective. Scale bars $=30 \mu \mathrm{m}$, inset scale bars $=10 \mu \mathrm{m}$.

$$
376 \times 760 \mathrm{~mm}(300 \times 300 \text { DPI })
$$


A)
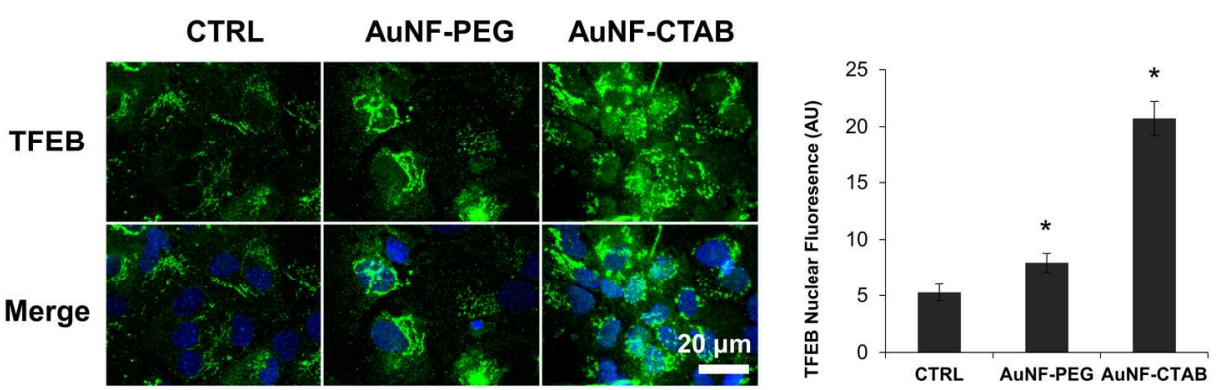

B)

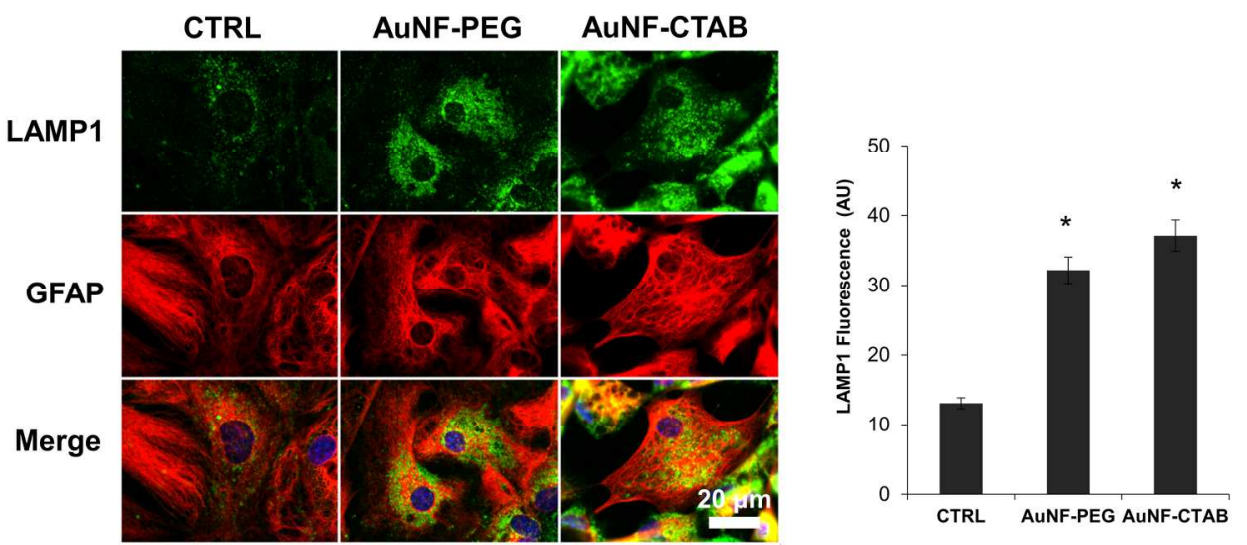

Figure 7) AuNF-PEG/CTAB (A) induces TFEB nuclear translocation. Graph represents percentage of cells with TFEB nuclear translocation, and (B) upregulates LAMP1 in glial cells. Graph represents cytosolic LAMP1 fluorescence intensity per cell. Cells were treated with 10uM AuNF-PEG/AuNF-CTAB for 24 hours in serumfree media. $\mathrm{N}=70$ cells per condition from two independent experiments, $\mathrm{N}=30$ cells per condition from three independent experiments. $* \mathrm{p}<0.05$, error bars represent SEM.

$183 \times 134 \mathrm{~mm}(300 \times 300 \mathrm{DPI})$ 


\section{Organotypic and primary neural cultures as a tool to assess effects of different gold nanostructures on glia and neurons}

Jeff Ji ${ }^{\mathrm{a}}$, Alexandre Moquin ${ }^{\mathrm{a}}$, Philip KY Chang ${ }^{\mathrm{a}}$, Rodolphe Antonine ${ }^{\mathrm{b}}$, Julia Luo ${ }^{\mathrm{a}}$, R. Anne McKinney ${ }^{\mathrm{a}}$, and Dusica Maysinger ${ }^{\mathrm{a},{ }^{*}}$

${ }^{a}$ Department of Pharmacology \& Therapeutics, McGill University, Montreal, Canada

${ }^{b}$ CNRS, Institut Lumière Matière, Université Lyon, Université Claude Bernard Lyon 1, Lyon, France

*Corresponding author: dusica.maysinger@megill.ca 

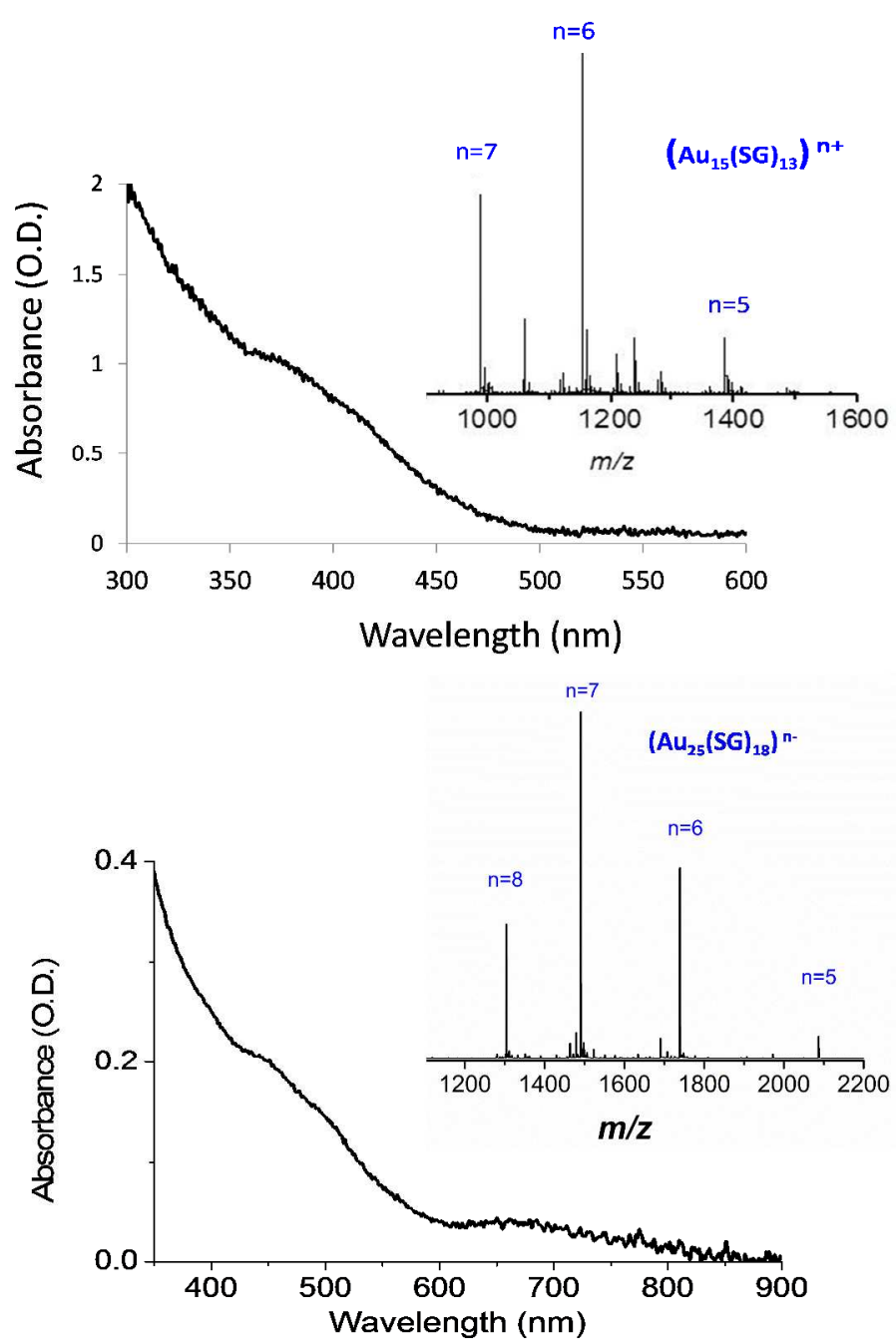

Supplemental Figure 1) UV-Vis absorption spectrum and (inset) electrospray ionization mass spectrum of Au-nanoclusters-GSH in water. From mass spectrometry, the nanocluster composition can clearly be assigned to $\mathrm{Au}_{15} \mathrm{SG}_{13}$ (a) and $\mathrm{Au}_{25} \mathrm{SG}_{18}$ (b). Mass spectrometry as a function of the $\mathrm{pH}$ of solution $(\mathrm{pH}=7.4$ and $\mathrm{pH}=5.5)$ showed that the cluster is not fragmented and intense peaks corresponding to different charge states of Au15SG13 are observed in both $\mathrm{pH}$ values [Hamouda et al. International Journal of Mass Spectrometry 335 (2013) 1-6]. 


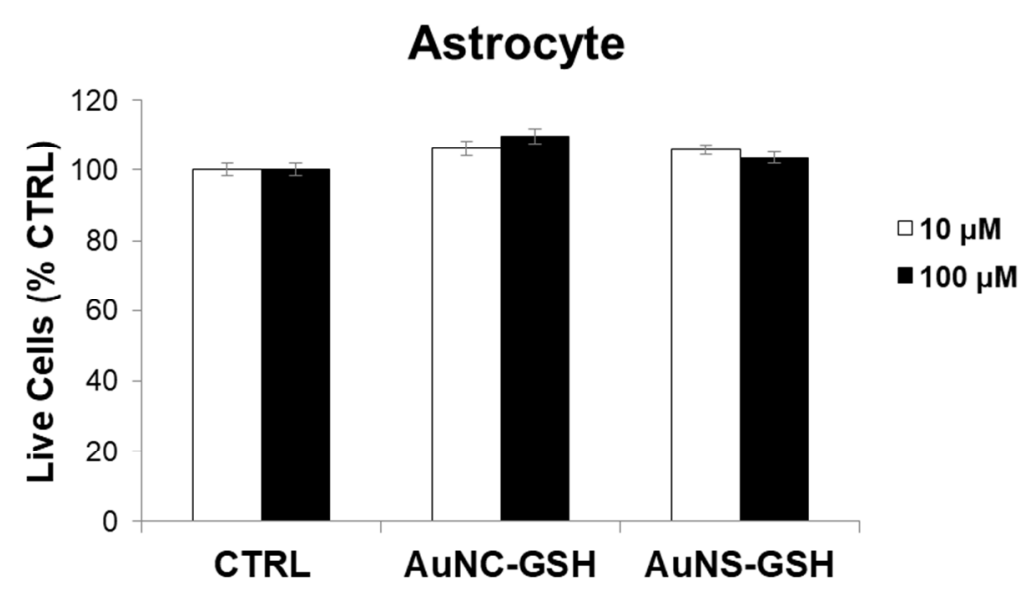

Supplemental Figure 2) Toxicity of GSH-coated AuNP in astrocytic cultures. Primary astrocytes were treated with 10 with $100 \mu \mathrm{M}$ Au-nanoclusters/S-GSH for 24h. N=2 independent experiments per condition. There was no loss of neurons in these cultures. JEFF: Show a bar graph for all conditions that there is no loss of neurons; Use same font in bar graphs. Add NC
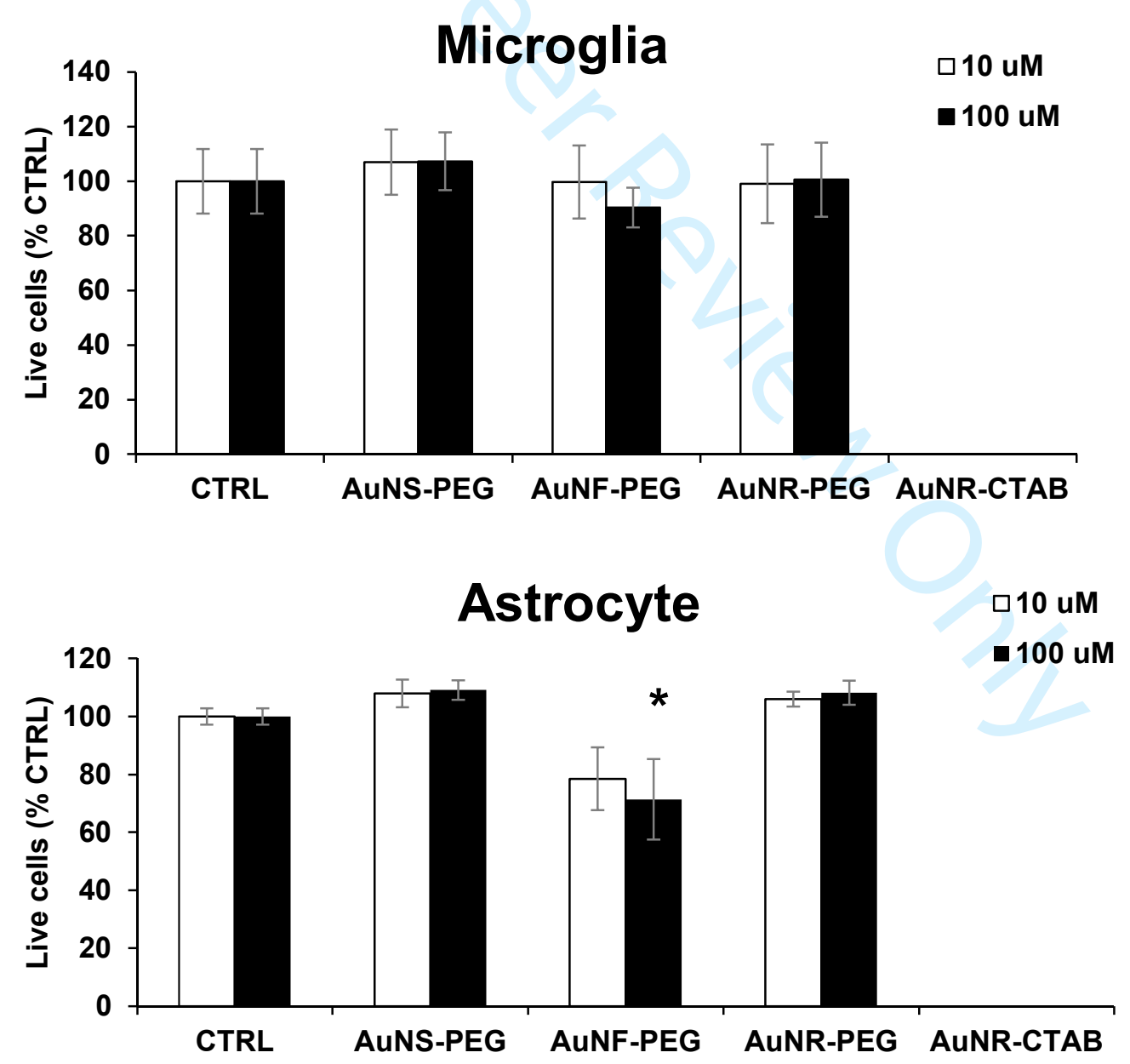

Supplemental Figure 3) Toxicity of PEG-coated AuNP in astrocytic/microglial cultures. Primary astrocytes or microglia were treated with 10 with $100 \mu \mathrm{M}$ AuNP-spheres/F/R$\mathrm{PEG} / \mathrm{CTAB}$ and for $24 \mathrm{~h}$. $\mathrm{N}=4$ independent experiments per condition for both astrocytes and microglia. There was no loss of neurons even in those cultures treated with AuNP-flowers-PEG 
at $100 \mu \mathrm{M}$. The treatments with AuNP-rods-CTAB at $10 \mu \mathrm{M}$ and $100 \mu \mathrm{M}$ eliminated neural cells beyond the limit of detection.

A)

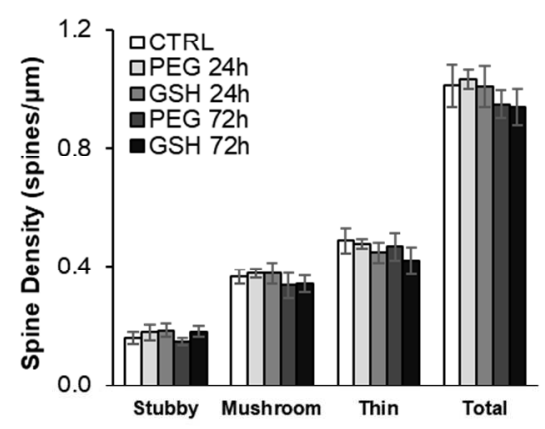

C)

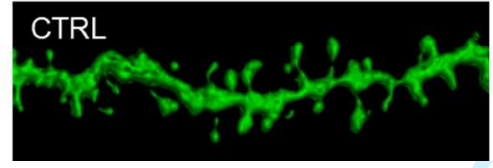

B)

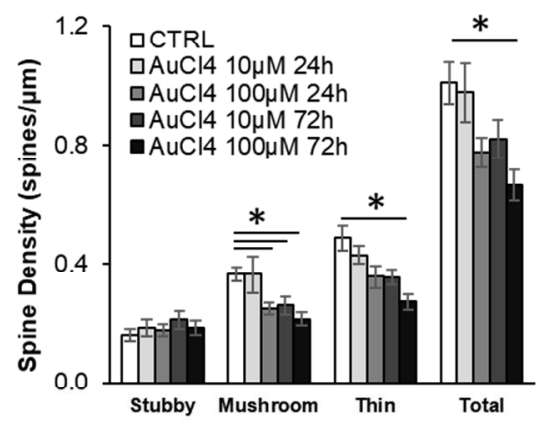

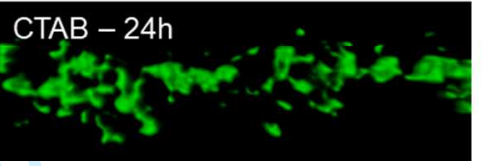

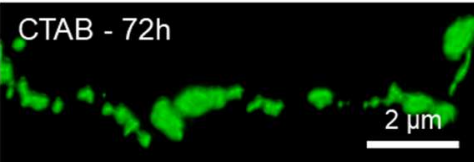

Supplemental Figure 4) Effects of PEG, GSH, CTAB and AuCl4 on hippocampal spine density. Hippocampal slice cultures were exposed to uncoupled PEG, GSH, and CTAB (2 $\mu \mathrm{M}$ PEG, $9 \mu \mathrm{M}$ GSH, and $1 \mu \mathrm{M} \mathrm{CTAB}$ ) at the highest equivalent concentration linked with AuNP as well as $10 \mu \mathrm{M}$ and $100 \mu \mathrm{M} \mathrm{HAuCl}_{4}$ for $24 \mathrm{~h}$ and $72 \mathrm{~h}$. A-B) Quantification of spine subtype and total density of hippocampal dendritic spines exposed to PEG, GSH, and AuCl4. n>5 dendrites per condition. * denotes $\mathrm{p}<0.05$. While PEG and GSH did not significantly alter spine density, uncoupled CTAB caused profound morphological distortions and fragmentation of the dendritic spines (C); quantitative assessment of spine subtypes was not possible. $\mathrm{HAuCl}_{4}$ reduced spine density in a time and concentration dependent manner. 
Supplemental Table 1) Concentration of elemental Au and AuNP

\begin{tabular}{|c|c|c|c|}
\hline Nanoparticles & $\begin{array}{c}\text { Molarity by Au } \\
\text { content (moles/L) }\end{array}$ & $\begin{array}{c}\text { Molarity by particle } \\
\text { number (moles/L) }\end{array}$ & Hydrodynamic sizes \\
\hline $\begin{array}{c}\text { Au-nanoclusters- } \\
\text { GSH } \\
\mathrm{Au}_{15} \mathrm{SG}_{13}\end{array}$ & 1 & $6.7 \mathrm{E}-2$ & $2.9 \mathrm{~nm}$ \\
\hline $\begin{array}{c}\text { Au-nanoclusters- } \\
\text { GSH } \\
\mathrm{Au}_{25} \mathrm{SG}_{18}\end{array}$ & 1 & $4 \mathrm{E}-2$ & $3.3 \mathrm{~nm}$ \\
\hline $\begin{array}{c}\text { AuNP-spheres- } \\
\text { PEG }\end{array}$ & 1 & $9.8 \mathrm{E}-6$ & $36.1 \mathrm{~nm}$ \\
\hline $\begin{array}{c}\text { AuNP-spheres- } \\
\text { GSH }\end{array}$ & 1 & $9.8 \mathrm{E}-6$ & $39.1 \mathrm{~nm}$ \\
\hline AuNP-rods-GSH & 1 & $5.4 \mathrm{E}-6$ & $29.5 \mathrm{~nm}$ \\
\hline AuNP-rods-PEG & 1 & $5.4 \mathrm{E}-6$ & $21.6 \mathrm{~nm}$ \\
\hline $\begin{array}{c}\text { AuNP-flowers- } \\
\text { GSH }\end{array}$ & 1 & $5.2 \mathrm{E}-8$ & $124 \mathrm{~nm}$ \\
\hline $\begin{array}{c}\text { AuNP-flowers- } \\
\text { PEG }\end{array}$ & 1 & $5.2 \mathrm{E}-8$ & $134.8 \mathrm{~nm}$ \\
\hline
\end{tabular}

N.B. Please note that the number of nanoparticles for the same Au concentration is within low nanomolar to picomolar range if expressed as per nanoparticle concentration (e.g. $100 \mu \mathrm{M} \mathrm{Au}=$ 6.7 E-9 M Au-nanoclusters. $100 \mu \mathrm{M} \mathrm{Au}=5.2 \mathrm{E}-12 \mathrm{M}$ AuNP-flowers). Conversions from $\mathrm{Au}$ concentrations into AuNP concentrations are based on data from UV-Vis absorption spectra, ICP-MS, and TEM. 
Supplemental Table 2) DLS of AuNP exposed to water, cell culture media, and cell culture media supplemented with $10 \%$ serum proteins at times $0 \mathrm{~h}$ and $24 \mathrm{~h}$. Nanoparticles were all diluted to $100 \mu \mathrm{M}$ Au.

\begin{tabular}{|c|c|c|c|c|c|c|}
\hline & \multicolumn{3}{|l|}{$\mathrm{dH}_{2} \mathrm{O}(0 \mathrm{~h})$} & \multicolumn{3}{|c|}{$\mathrm{dH}_{2} \mathrm{O}(24 \mathrm{~h})$} \\
\hline & diameter & PDI & kcps & diameter & PDI & kcps \\
\hline Au-nanocluster-GSH & $\mathbf{0}$ & 0.005 & 0.577 & 49.8 & 0.404 & 4 \\
\hline AuNP-spheres-GSH & 39.7 & 0.292 & 82.6 & 40 & 0.285 & 54.6 \\
\hline AuNP-spheres-PEG & 36.1 & 0.096 & 27.3 & 35.5 & 0.144 & 25.2 \\
\hline AuNP-rods-GSH & 29.5 & 0.377 & 1000 & 29.3 & 0.375 & 981.4 \\
\hline AuNP-rods-PEG & 21.6 & 0.384 & 958.8 & 23.8 & 0.381 & 738.7 \\
\hline AuNP-flowers-GSH & 124 & 0.180 & 611.3 & 124.4 & 0.182 & 562.8 \\
\hline \multirow[t]{3}{*}{ AuNP-flowers-PEG } & 134.8 & 0.186 & 843.7 & 137.8 & 0.177 & 624.2 \\
\hline & \multicolumn{3}{|l|}{ DMEM (0h) } & \multicolumn{3}{|c|}{ DMEM (24h) } \\
\hline & diameter & PDI & kcps & diameter & PDI & kcps \\
\hline DMEM & 566.1 & 0.442 & 5 & & & \\
\hline Au-nanocluster-GSH & 429.7 & 0.312 & 6.1 & 36 & 0.363 & 29.3 \\
\hline AuNP-spheres-GSH & 412.7 & 0.157 & 1100 & 434.6 & 0.172 & 945.5 \\
\hline AuNP-spheres-PEG & 43.9 & 0.216 & 29.6 & 44.1 & 0.257 & 21.8 \\
\hline AuNP-rods-GSH & 23.6 & 0.382 & 991.9 & 26.5 & 0.385 & 634.5 \\
\hline AuNP-rods-PEG & 21.8 & 0.38 & 974.4 & 27.7 & 0.377 & 636.3 \\
\hline AuNP-flowers-GSH & 119.6 & 0.183 & 739.7 & 116.2 & 0.173 & 277.2 \\
\hline \multirow[t]{3}{*}{ AuNP-flowers-PEG } & 135.1 & 0.171 & 830.8 & 120.4 & 0.157 & 373.8 \\
\hline & \multicolumn{3}{|c|}{ DMEM+ FBS (0h) } & \multicolumn{3}{|c|}{ DMEM+FBS (24h) } \\
\hline & diameter & PDI & kcps & diameter & PDI & kcps \\
\hline DMEM+FBS 10\% & 23.3 & 0.293 & 19 & 8 & & \\
\hline $\mathrm{Au}$-nanocluster-GSH & 22.8 & 0.318 & 28.8 & 27.4 & 0.329 & 31.8 \\
\hline AuNP-spheres-GSH & 56.5 & 0.287 & 157.1 & 58.3 & 0.286 & 106.2 \\
\hline AuNP-spheres-PEG & 28.4 & 0.269 & 48.8 & 28.3 & 0.268 & 46.5 \\
\hline AuNP-rods-GSH & 24.3 & 0.377 & 921.1 & 24.1 & 0.382 & 880 \\
\hline AuNP-rods-PEG & 21.4 & 0.378 & 882.2 & 23.2 & 0.384 & 725.7 \\
\hline AuNP-flowers-GSH & 121.6 & 0.213 & 741.6 & 119.4 & 0.226 & 852.9 \\
\hline AuNP-flowers-PEG & 134.1 & 0.204 & 882.8 & 121.9 & 0.204 & 870 \\
\hline
\end{tabular}

DLS assumes a spherical shape for particles analysed, therefore the DLS data for AuNP-rods is presented to portray size distribution only, TEM was used to better portray the shape and sizes of the non-spherical particles (Figure 2). 